\title{
Stem cell-derived and circulating exosomal microRNAs as new potential tools for diabetic nephropathy management
}

\author{
Lei Peng ${ }^{1 \dagger}$, Yu Chen ${ }^{2 \dagger}$, Shaoging Shi ${ }^{3^{*}}$ and Heling Wen ${ }^{2^{*}}$ (D)
}

\begin{abstract}
Background: Despite major advances in the treatment of diabetic nephropathy (DN) in recent years, it remains the most common cause of end-stage renal disease. An early diagnosis and therapy may slow down the DN progression. Numerous potential biomarkers are currently being researched. Circulating levels of the kidney-released exosomes and biological molecules, which reflect the DN pathology including glomerular and tubular dysfunction as well as mesangial expansion and fibrosis, have shown the potential for predicting the occurrence and progression of DN. Moreover, many experimental therapies are currently being investigated, including stem cell therapy and medications targeting inflammatory, oxidant, or pro-fibrotic pathways activated during the DN progression. The therapeutic potential of stem cells is partly depending on their secretory capacity, particularly exosomal microRNAs (Exo-miRs). In recent years, a growing line of research has shown the participation of Exo-miRs in the pathophysiological processes of DN, which may provide effective therapeutic and biomarker tools for DN treatment.

Methods: A systematic literature search was performed in MEDLINE, Scopus, and Google Scholar to collect published findings regarding therapeutic stem cell-derived Exo-miRs for DN treatment as well as circulating Exo-miRs as potential DN-associated biomarkers.

Findings: Glomerular mesangial cells and podocytes are the most important culprits in the pathogenesis of DN and, thus, can be considered valuable therapeutic targets. Preclinical investigations have shown that stem cell-derived exosomes can exert beneficial effects in DN by transferring renoprotective miRs to the injured mesangial cells and podocytes. Of note, renoprotective Exo-miR-125a secreted by adipose-derived mesenchymal stem cells can improve the injured mesangial cells, while renoprotective Exo-miRs secreted by adipose-derived stem cells (Exo-miR-486 and Exo-miR-215-5p), human urine-derived stem cells (Exo-miR-16-5p), and bone marrow-derived mesenchymal stem cells (Exo-miR-let-7a) can improve the injured podocytes. On the other hand, clinical investigations have indicated that circulating Exo-miRs isolated from urine or serum hold great potential as promising biomarkers in DN.
\end{abstract}

Keywords: Biomarker, Exosome, Diabetic nephropathy, microRNA, Serum, Stem cell, Urine

*Correspondence: sqs621@yeah.net; kavincardio@sina.com

†Lei Peng and Yu Chen are co-first authors, and they contributed equally to this work

${ }^{2}$ Department of Cardiology, Sichuan Academy of Medical Science and Sichuan Provincial People's Hospital, Chengdu 610072, China

${ }^{3}$ Department of Pulmonary and Critical Care Medicine, The First Affiliated Hospital of Kunming Medical University, Kunming 650032, China

Full list of author information is available at the end of the article

\section{Key message}

Stem cell-derived and circulating Exo-miRs provide valuable insights to identify the ideal candidates for improving the therapeutic and diagnostic/prognostic goals in diabetic patients who are at a high risk of DN progression. original author(s) and the source, provide a link to the Creative Commons licence, and indicate if changes were made. The images or other third party material in this article are included in the article's Creative Commons licence, unless indicated otherwise in a credit line to the material. If material is not included in the article's Creative Commons licence and your intended use is not permitted by statutory regulation or exceeds the permitted use, you will need to obtain permission directly from the copyright holder. To view a copy of this licence, visit http://creativecommons.org/licenses/by/4.0/. The Creative Commons Public Domain Dedication waiver (http://creativeco mmons.org/publicdomain/zero/1.0/) applies to the data made available in this article, unless otherwise stated in a credit line to the data. 


\section{Background}

\section{The pathophysiology of diabetic nephropathy}

Diabetic nephropathy (DN) is the main reason for endstage renal disease (ESRD) worldwide, presenting a leading cause of morbidity and mortality in patients with either type I DM (T1DM) or type II DM (T2DM) [1]. DN is mainly characterized by functional and morphological abnormalities within the kidney. Morphological abnormalities include glomerular hypertrophy, podocyte injury and depletion, progressive accumulation of extracellular matrix (ECM), expansion of the mesangial matrix, and thickening of glomerular basement membrane (GBM), as well as glomerulosclerosis and tubulointerstitial fibrosis. Functional abnormalities including proteinuria, the reduced rate of glomerular filtration, as well as glomerular hyperperfusion and hyperfiltration occur before the initiation of morphological abnormalities [2]. Long-lasting hyperglycemia, high blood pressure, and inflammation are the major etiological factors responsible for $\mathrm{DN}$ development. These factors contribute to progressive and irreversible injury to the renal glomeruli and tubulointerstitial, causing the regression of renal function and the eventual renal failure [1].

When experiencing high-pressure conditions, podocytes and mesangial cells release various mediators that promote the functional and morphological alterations in the glomeruli [3]. These mediators include vascular endothelial growth factor A (VEGFA), transforming growth factor- $\beta 1$ (TGF- $\beta 1$ ), glomerular capillary remodeling cytokine, angiotensin II (Ang II) and angiotensinconverting enzyme (ACE), as well as pro-inflammatory cytokines such as chemokine ( $\mathrm{C}-\mathrm{C}$ motif) ligand 2/ monocyte chemoattractant protein-1 (CCL2/MCP-1) and interleukin-6 (IL-6) [4]. These mediators promote pathogenic alterations either directly via activation of cellular remodeling signaling pathways resulting in cellular morphological alterations and increasing ECM synthesis or indirectly by elevating oxidative stress through activating nicotinamide adenine dinucleotide phosphate hydrogen (NADPH) oxidase [4].

Hyperglycemia produces advanced glycation end products (AGEs) within plasma and tissues. AGEs promote kidney complications through two independent pathways. On the one hand, AGEs irreversibly attach to matrix proteins (laminin and type IV collagen) and inhibit their degradation via matrix metalloproteinases, which puts up fibrosis by the excessive deposition of ECM proteins $[5,6]$. On the other hand, AGEs also interact with their receptors expressed by podocytes and mesangial cells and, thereby, promote specific cellular responses including the secretion of pro-fibrotic cytokines, such as VEGF, connective tissue growth factor (CTGF), and TGF- $\beta 1$, as well as elevated expression of
NADPH oxidase. Altogether, these result in glomerular cell proliferation, expansion, or hypertrophy $[4,7]$.

Kidney inflammation also exerts a significant role in the progression of $\mathrm{DN}$. The progressive alternations in the glomerular function and structure result in the interstitial infiltration of inflammatory cells that exacerbate the DN progression through the secretion of proinflammatory and tissue remodeling cytokines. These molecules include tumor necrosis factor-alpha (TNF- $\alpha$ ), interferon- $\gamma$ (IFN- $\gamma$ ), IL-1, IL-6, and MCP-1, which can also induce oxidative stress via activating NADPH oxidase [8].

\section{Current and future biomarkers of DN}

The early detection of DN is a critical medical demand, not only to predict and prevent $\mathrm{DN}$ progression but also to further enhance patients' survival and decrease correlated morbidities. In clinical practice, DN diagnosis and prognosis are based on the presence of albuminuria, proteinuria, serum creatinine, blood urea nitrogen (BUN), and reduction of estimated glomerular filtration rate (eGFR), together with long-term diabetes. The DN severity is traditionally evaluated by measuring levels of urine albumin [urine albumin-to-creatinine ratio (UACR)]. The persistent microalbuminuria $(30-300 \mathrm{mg} / 24 \mathrm{~h})$ or macroalbuminuria ( $>300 \mathrm{mg} / 24 \mathrm{~h}$ ) has been widely used as a conventional biomarker of the early onset of $\mathrm{DN}$ and its progression to ESRD. However, in reality, kidney function is injured or even deteriorated before the detection of microalbuminuria/macroalbuminuria, and also there is conflicting evidence to the specificity and sensitivity of albuminuria $[9,10]$. Moreover, the gold standard for the diagnosis of $\mathrm{DN}$ is mainly based on pathological alterations in renal biopsy, which is along with the drawbacks of an invasive approach and the inability to track $\mathrm{DN}$ progression [11]. Thus, exploring noninvasive and more specific and sensitive biomarkers of early stages of DN and development to the ESRD is necessary.

Over the last decade, considerable efforts have been made to find urine or serum biomarkers for noninvasive detecting early steps of $\mathrm{DN}$ and the progressive decline of renal function in diabetic patients. The search for biomarkers has often relied on serum or urinary biological molecules reflecting aspects of DN pathology. In the early stages of $\mathrm{DN}$, a reduction in the number of podocytes often happens because of apoptosis or shedding of podocytes, which affects the glomerular filtration function. A growing body of research has shown the potentiality of urinary podocyte-specific proteins, including synaptopodin and nephrin, as noninvasive early biomarkers of glomerular damage in DN [12-20]. Of note, the urinary levels of these proteins were found to be extremely increased in $\mathrm{DN}$ patients 
even before proteinuria and indicated a strong correlation with UACR and eGFR [16-20].

Another pathological hallmark of DN complications is renal fibrosis resulting from ECM changes and mesangial expansion. Hyperglycemia upregulates the expression of TGF- $\beta 1$ and TNF- $\alpha$ that are known to be the most important cytokines involved in tubulointerstitial fibrosis and glomerulosclerosis [21, 22]. These cytokines promote the cell apoptosis and accumulation of ECM in the mesangium, which reduces the rate of glomerular filtration and increases the permeability of tubules, leading to renal failure. As reported by independent studies, urinary and serum levels of both TGF- $\beta 1$ [23] and TNF- $\alpha$ [24-26] are significantly higher in patients with microalbuminuria than in patients with normoalbuminuria and healthy subjects. Of note, urinary levels of these cytokines were found to be gradually elevated alongside the progression of $\mathrm{DN}$, suggesting these cytokines as sensitive biomarkers in the early stage of DN [27-29].

Notably, tubulointerstitial damage plays a key role in the early stages of DN development, even before the evident glomerular dysfunction and proteinuria [15, 30]. The degree of tubulointerstitial damage is highly correlated with the renal prognosis. Thus, tubular markers of renal injury may be capable of reflecting the degree of sustained renal damage in diabetic patients. Neutrophil gelatinase-associated lipocalin (NGAL) is expressed in the renal tubular cells in response to kidney damage. NGAL has been documented as a promising new biomarker for the early stages of tubular renal injury [3134]. Of note, the increased urinary NGAL correlates with the reduction in eGFR in diabetic patients with macroor microalbuminuria [35]. Importantly, both urinary and serum NGAL indicate an elevating trend along with the decline in eGFR and albuminuria during the DN progression [36]. The urinary level of NGAL has also been found to be elevated even before the decline in traditional biomarkers (eGFR and albuminuria) in diabetic patients [3]. Thus, NGAL may be a useful biomarker for the early diagnosis of tubulointerstitial damage in patients with a high risk of progression to $\mathrm{DN}$.

Despite the presence of the aforementioned potential biomarkers, but so far no biomarkers have been implemented in clinical care for the reason of lack of validation, and confirmation of their added value over that of the existing traditional biomarkers has yet to be proven [37]. Thus, alternative research is now focusing on emerging biomarkers to improve the sensitivity of biomarkers for predicting diabetic patients who will develop $\mathrm{DN}$ or are at a high risk of progressing to ESRD. These include circulating microRNAs (miRs) and extracellular vesicles (EVs) such as exosomes.

\section{Current and emerging therapies for DN}

There is no cure available for DN and the current management relies on optimized blood pressure and glycemic control using agents with renoprotective properties. The renin-angiotensin-aldosterone system (RAAS) inhibitors (angiotensin-II receptor blockers [ARB] and angiotensin-converting enzyme [ACE] inhibitors) are the first-line blood pressure-lowering agents administrated for DN treatment [20-23]. The beneficial effects of RAAS inhibitors, such as captopril (ACE inhibitor) [38], irbesartan (ARB) [39, 40], and losartan (ARB) [41], have been documented in various randomized clinical trials. The RAAS blockade has been found to slow the rate of progression to albuminuria and decrease the risk of serum creatinine elevation and the complex outcome of ESRD or death [38-41]. The therapeutic efficacy of RAAS inhibitors in DN patients is because of their capability to decrease not only systemic blood pressure but also the glomerular hyperfiltration and the intraglomerular pressure by vasodilation of the efferent arteriole [42]. However, the administration of an ARB or ACE inhibitor cannot completely terminate the $\mathrm{DN}$ progression. Notably, a combination of ACE inhibitors and ARBs has also been found to be associated with an elevated risk of adverse effects such as acute kidney injury and hyperkalemia [43-45]. Recently, the novel mineralocorticoid receptor antagonists (MRAs), such as finerenone [46] and esaxerenone [47], have attracted much attention for intensifying the RAAS inhibition. An addition of MRAs to the standard ARB treatment or ACE inhibitor has been found to significantly reduce UACR, albuminuria, the decline in eGFR, and the risk of the complex outcome of renal failure or renal-caused death [46-48].

Moreover, glucagon-like peptide-1 (GLP-1) receptor agonists and sodium-glucose co-transporter 2 (SGLT2) inhibitors have shown anti-proteinuric/albuminuric and renoprotective effects beyond their glucose-lowering effects in DN patients, through the monotherapy or on the top of RAAS inhibition. Several randomized controlled trials have reported a significantly lower risk of incident or worsening nephropathy or death in T2DM patients who were treated with SGLT2 inhibitors empagliflozin [EMPA-REG OUTCOME trial] [49], canagliflozin [the CANVAS Program] [50], or dapagliflozin [the DECLARE-TIMI 58 trial [51] and DAPA-CKD trial [52]]. Recently, the CREDENCE trial indicated clear benefits of canagliflozin against elevated levels of the creatinine, the composite endpoint of ESRD, or renal-caused death in T2DM patients with macroalbuminuria [53]. Currently, the impact of empagliflozin on the progression of renal disease and the occurrence of death in diabetic and non-diabetic patients is being evaluated in the ongoing EMPA-KIDNEY trial (NCT03594110). Another type 
of glucose-lowering agents, GLP-1 receptor agonists have also shown an association with a lower risk of newonset macroalbuminuria and a significant decrease in the progression of UACR in the macroalbuminuric condition, with moderate impacts on eGFR in T2DM patients [54-56]. Notably, an ongoing randomized controlled trial is currently being studied the long-term impacts of GLP-1 receptor agonist semaglutide on the progression to ESRD, rate of eGFR reduction, or death from renal disease (NCT03819153).

Nonetheless, many DN patients eventually progress to ESRD. Thus, there is an essential need for novel therapies that will refine renal function, decrease disease progression, and importantly enhance renal survival in DN. Currently, several therapeutic approaches are being investigated and may provide the foreseeable future therapies for DN. Generally, emerging treatments include the existing and under-investigation medications that target inflammatory, oxidant, or pro-fibrotic pathways.

Apoptosis signal-regulating kinase 1 (ASK1) is a key pathway associated with oxidative stress in DN. ASK1 can trigger the generation of pro-inflammatory and pro-fibrotic mediators leading to inflammation, matrix remodeling, fibrosis, and apoptosis [57]. Selonsertib (GS-4997) is an ASK1 inhibitor that has been found to improve kidney functional parameters such as eGFR, serum creatinine, and proteinuria in both animal models [58] and patients with renal disease (NCT02177786).

Moreover, phosphodiesterase inhibitors including pentoxifylline (NCT00663949) [59, 60], CTP-499 (NCT01487109, NCT01328821) [61], and PF-00489791 (NCT01200394) [62] are mainly recognized for their anti-inflammatory activity. These agents are associated with a significant decrease in the eGFR decline and UACR as well as a marked alleviation in levels of inflammatory markers including serum $\mathrm{C}$-reactive protein (CRP) and urinary CCL2/MCP-1.

The pro-inflammatory chemokine $(\mathrm{C}-\mathrm{C}$ motif) receptor type 2 (CCR2) and CCL2/MCP-1 play important roles in the pathogenesis of $\mathrm{DN}$. The overexposure to the high glucose and/or filtered proteins induces the production and release of chemokines by tubular cells and podocytes, resulting in the recruitment of inflammatory cells and renal impairment [57]. The preliminary data from both animal models and clinical trials have demonstrated the renoprotective effects of chemokine inhibitors in DN. Of note, the CCR2 inhibitor CCX140-B [63] and CCL2 inhibitor NOX-E36 [64] have been found to improve proteinuria, the podocyte damage, the number of inflammatory macrophages, and the glomerular endothelial glycocalyx in the experimental mouse models of DN. On top of current standard treatments, CCX140B (NCT01447147) [65] and NOX-E36 [66] were found to significantly slow the eGFR decline and reduce albuminuria in T2DM patients with nephropathy. Another potential target is the endocannabinoid system (ECS). Despite its major expression and function in the central nervous system, the ECS also plays a role in the kidney and especially in DN pathogenesis. The cannabinoid receptor 1 (CB1R) and 2 (CB2R) show opposite behaviors in DN. Podocytes overexpress CB1R in both human and investigational DN, whereas podocyte expression of CB2R is significantly downregulated in patients with advanced DN. Of note, CB1R signaling elevates the fibrogenesis, inflammation, and oxidative stress, while CB2R shows opposite impacts [67]. Both peripheral CB1R antagonists and CB2R agonists decreased albuminuria, inflammation, and renal fibrosis, and reversed alterations in the renal function in animals with persisted albuminuria [68, 69]. These agents are currently under clinical investigations to confer the proof of tolerability and safety, particularly CNS safety.

On the other hand, endothelins are the small vasoactive peptides that exert multiple pathophysiological effects, including damage to podocytes (nephron shedding, cytoskeletal disruption, and proteinuria), mesangium (proliferation and ECM accumulation), and tubulointerstitium (fibrosis) as well as inducing inflammatory cell infiltration [70]. In experimental studies, antagonists of endothelin receptors improved the renal morphology and function and reduced albuminuria through multiple mechanisms, including attenuated damage to mesangial cells, podocytes, renal tubules, and glycocalyx [71-74]. Of note, atrasentan is a selective endothelin-receptor antagonist with renoprotective features, which could reduce albuminuria in DN patients at a high risk of developing ESRD [75].

Besides approaches aimed to alleviate oxidative stress and inflammation in the kidney, novel potential therapeutic strategies based on stem cells, exosomes, and miRs are on the horizon with promising preclinical findings. With advances in stem cell technology, stem cell-based regenerative medicine has shown the potential as a therapeutic approach. There is a growing number of preclinical studies showing successful outcomes of stem cell transplantation for halting the progression of DN [76-92]. In brief, these studies provided evidence that stem cell therapy can improve functional indices, such as the elevation in glomerular filtration and the reduction in albuminuria and glomerulosclerosis. The studies demonstrated an improvement in renal histology and the suppressing of nephrocyte death, oxidative stress, inflammation, and renal fibrosis. Moreover, stem cell therapy was found to preserve renal mass, upregulate the expression of podocyte and tubular epithelial genes, augment levels of growth factors within the kidneys, reduce endothelium 
damage, and ameliorate tubular glucotoxicity by reducing the uptake of cellular glucose in the kidneys. These preclinical findings have been further supported by a clinical study (NCT02585622) that showed the stem cell transplantation could improve the eGFR, without significant treatment-related severe adverse events, in diabetic patients with progressive renal disease [93]. Recent studies suggest that the therapeutic potential of stem cells has been majorly dependent on their secretory capacity, particularly exosomes [94].

Exosomes are lipid bilayer EVs secreted by a broad range of cell types. These vesicles mirror the molecular content of donor cells and participate in cellular crosstalk between both neighboring and distant cells under physiological and pathological conditions. Exosomemediated intercellular communication stems from its capacity in cell-to-cell transferring of biological information. miRs, a key functional cargo of exosomes, are principal negative regulators of the genome, which are mostly dysregulated in pathological conditions. The selective packaging and intercellular delivery of miRs by exosomes have encouraged deeper research of exosomal miRs (Exo-miRs), both as biomarkers and therapeutic agents [95-100]. A growing number of preclinical and clinical investigations indicates the impressive roles of Exo-miRs in $\mathrm{DN}$ progression. On the one hand, it has been recently shown that stem cell-derived exosomes contain renoprotective miRs posing therapeutic impacts on DN. On the other hand, various preclinical and clinical studies have reported that circulating Exo-miRs isolated from urine or bloodstream hold great potential as biomarkers in DN.

The present review highlights stem cell-derived ExomiRs reported as the potential therapeutic tools for treating DN. In sum, an overview of the findings showed that exosomes derived from different sources of stem cells deliver distinct patterns of renoprotective miRs to the target cells that are injured in DN. The second part of this review article focuses on the studies that investigated the potentiality of circulating Exo-miRs as non-invasive biomarkers for the early diagnosis/prognosis of DN progression in diabetic patients.

\section{Methods}

This review article aimed to seek renoprotective stem cell-derived Exo-miRs for treating DN as well as circulating Exo-miRs showing biomarker features for diagnosing/predicting DN progression in diabetic patients. To this end, a systematic literature search was performed in MEDLINE (http://www.ncbi.nlm.nih.gov/ pubmed), Scopus (http://www.scopus.com), and Google Scholar (http://scholar.google.com), without any language restrictions, to identify all published articles dealing with the aims of the present study. Two independent searches were carried out from inception to July 2021 using the terms [(diabetic nephropathy OR diabetic renal disease OR diabetic kidney disease) AND (exosome) AND (microRNA OR miR) AND (stem cell)] as well as [(diabetic nephropathy OR diabetic renal disease OR diabetic kidney disease) AND (exosome) AND (microRNA OR miR) AND (circulation OR blood OR serum OR plasma OR urine)] in titles and abstracts. Based on the abstract, documents which include the following criteria were collected for the full-text screening: original articles reported the in vitro, in vivo, and clinical studies regarding the renoprotective stem cell-derived ExomiRs in diabetic condition as well as serum/plasma or urinary-derived Exo-miRs showing biomarker capacity for detecting DN and its progression. The exclusion criteria were as follows: full text inaccessible; duplicate and non-original studies; not written in the English language; and only evaluated exosomes or miRs.

\section{Stem cell-derived Exo-miRs posing therapeutic effects on DN}

Stem cell-derived exosomes have been found to not only recapitulate the therapeutic activities of parent cells but also provide advantages over them [101]. They are less complex and smaller than cells and have the potential to circumvent drawbacks of cell therapy, such as limited engraftment and poor survival and differentiation of stem cells caused by the diabetic microenvironment, risk of differentiation into unwanted cell lineages and formation of ectopic tissue, risk of tumorigenicity and genetic aberrations, as well as ethical and safety challenges [101]. Notably, exosomes have autonomous targeting capabilities and can home to a specific lesion tissue [101]. Exosomes have been found to internalize in a cell type-specific route that relies on recognition of exosomal surface ligands/receptors by the target cell or tissue. For instance, SDF- $1 \alpha /$ CXCR 4 interaction was exhibited to mediate the selective delivery of endothelial cell-derived exosomes to the kidney [102]. As discussed in the following subsections, exosomes released from various types of stem cells have been found to exert beneficial effects in DN by transferring renoprotective miRs to injured podocytes and mesangial and tubular cells (Table 1 and Fig. 1).

\section{Stem cell-derived Exo-miRs posing protective effects on mesangial cells}

The glomerular mesangial cells (GMCs) generate the mesangial matrix, provide the structural guard to the glomerular tuft, communicate with other glomerular cells via releasing soluble mediators, and assist the glomerular capillary flow by their contractile ability. Hyperglycemia promotes GMC activation, which commonly leads to immoderate cell proliferation and hypertrophy 
Table 1 Renoprotective Exo-miRs derived from stem cells

\begin{tabular}{|c|c|c|c|c|c|}
\hline $\begin{array}{l}\text { Source of stem } \\
\text { cell }\end{array}$ & Exo-miR & In vitro target cell & In vivo clinical effects & $\begin{array}{l}\text { Molecular target of } \\
\text { Exo-miR }\end{array}$ & Refs \\
\hline adMSC & miR-125a & Mesangial cells & $\begin{array}{l}\text { Reducing the mesangial hyperplasia, } \\
\text { the expansion rate of the mesangial matrix, and } \\
\text { kidney fibrosis in DN rats }\end{array}$ & HDAC1 & [107] \\
\hline \multirow[t]{3}{*}{ ADSC } & miR-486 & Podocyte & Improving the GFB function in DN mice & Smad1 & [118] \\
\hline & miR-26a-5p & Podocyte & ND & TLR4 & [119] \\
\hline & miR-215-5p & Podocyte & - & ZEB2 & [123] \\
\hline hUSCs & miR-16-5p & Podocyte & Improving the GFB function in DN rats & VEGFA & [130] \\
\hline \multirow[t]{4}{*}{ BMSCs } & miR-let-7a & Podocyte & Improving the GFB function in DN rats & USP22 & [136] \\
\hline & miR-222 & Mesangial cells & ND & STAT5 & [106] \\
\hline & miR-125b & Tubular cells & ND & TRAF6 & [146] \\
\hline & miR-let7c & Tubular cells & $\begin{array}{l}\text { The reduction of the ECM accumulation and } \\
\text { the amelioration of the fibrosis }\end{array}$ & TGF- $\beta 1$ & [147] \\
\hline
\end{tabular}

Not defined, ND; Adipose-derived mesenchymal stem cells, adMSCs; adipose-derived stem cells, ADSCs; human urine-derived stem cells, hUSCs; bone marrow mesenchymal stem cells, BMSCs; exosomal microRNA, Exo-miR; Histone deacetylase 1, HDAC1; zinc finger E-box-binding homeobox-2, ZEB2; vascular endothelial growth factor A, VEGFA; signal transducer and activator of transcription 5, STAT5; TNF Receptor Associated Factor 6, TRAF6; toll-like receptor 4, TLR4; transforming growth factor beta 1, TGF- $\beta 1$

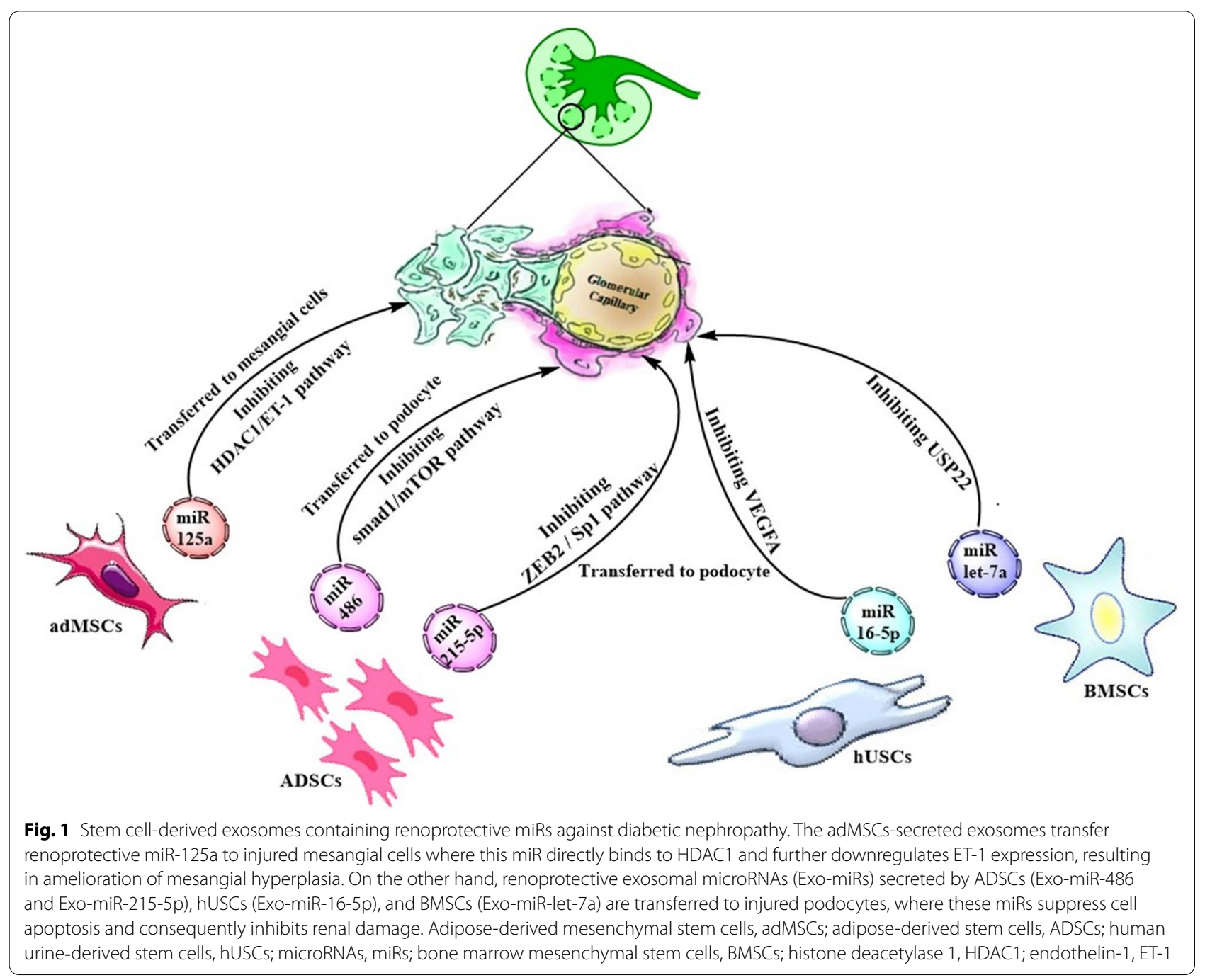


as well as the excessive production of the mesangial matrix, through the upregulating glucose transporters and an elevation in the entrance of glucose into the cells [103]. The mesangial matrix expansion leads to the glomerular capillary blockade and a progressive reduction in the filtration surface of the glomerulus [104]. If activation of GMCs is continuing, expansion of glomerular mesangium and the increased accumulation of the mesangial matrix in the interstitial space will cause progressive scarring and fibrosis of glomerular mesangium, a major hallmark of DN known as glomerulosclerosis [105]. TGF $\beta$ is the most relevant regulatory cytokine in the onset of renal fibrosis and collagen accumulation in GMCs under hyperglycemic conditions. Notably, it has been shown that EVs secreted from bone marrow mesenchymal stem cells (BMSCs) protect GMCs from the high glucose (HG)-induced damage via the transfer of miR-222. By targeting and downregulating STAT5, miR222 was found to significantly reduce TGF- $\beta$ expression and collagen production within GMCs [106]. In addition, it was recently reported that exosomes released from adipose-derived mesenchymal stem cells (adMSCs) could significantly inhibit the excessive proliferation of HGtreated GMCs mimicking a DN-like condition in vitro. Of note, IL-6, a typical autocrine growth factor inducing glomerular damage and mesangial hyperplasia, was found to be highly increased in HG-treated GMCs. The adMSC-exosome treatment could significantly inhibit the HG-induced IL-6 expression in GMCs [107]. It was further supported by the in vivo study that showed the treatment with adMSC-exosomes effectively alleviated mesangial hyperplasia, the expansion rate of the mesangial matrix, and kidney fibrosis in STZ-induced DN rats. These effects were along with a significant reduction in serum creatinine, urinary protein, and UACR, as well as a considerable amelioration of kidney pathological symptoms including capillary lumen shrinking, infiltration of inflammatory cells, and renal tubular damage [107]. Notably, elevated levels of collagen I and fibronectin contribute to the renal fibrosis and the impaired renal function and are key biomarkers for the mesangial matrix expansion [108]. Of note, adMSC-exosomes were found to significantly inhibit the upregulation of these fibrosis-related factors in the kidney of $\mathrm{DN}$ rats and in vitro in HG-treated GMCs [107], supporting the protective effect of adMSC-exosomes on renal fibrosis and function. Importantly, miR-125a was found to be responsible for the renoprotective effects mediated by adMSC-exosomes. Notably, the downregulation of miR125a inhibited the protective effects of adMSC-exosomes in the DN rat model and in HG-treated GMCs [107]. miR-125a had also been already shown by other studies to be carried by MSC-exosomes [109] and to play a key role in DN patients, with a significant preventive effect on the disease progression [110]. The histone deacetylase 1 (HDAC1) has been found to be a direct mRNA target of miR-125a in the kidney tissues in rats and in GMCs [107]. HDAC1 can exacerbate DN progression through upregulating endothelin-1 (ET-1). adMSC-Exo-miR125a was found to protect the kidney injury in DN rats through inhibiting the HDAC1/ET-1 axis [107]. Supporting is convincing evidence that shows a firm association between ET-1 with diabetes and its complications. ET1 has been reported to promote insulin resistance [111], to elevate the glomerular permeability and in turn elevate the serum level of creatinine [112], to correlate with the proteinuria level in DN patients [113], to induce proliferation of mesangial cells and accumulation of mesangial matrix [114], and to play a pro-fibrotic role in diabetic complications [115]. In conclusion, abovementioned findings indicate that exosomes released from adMSC provide the promising tool to ameliorate the renal fibrosis and improve the kidney function through transferring miR-125a to GMCs where directly binds to HDAC1 and further downregulates ET-1 expression.

\section{Stem cell-derived Exo-miRs posing protective effects on podocytes}

The glomerular filtration barrier (GFB) is specialized to permit substantial filtration of water and solutes in the kidney. The GFB dysfunction is a typical clinical symptom of DN, which is accompanied with microalbuminuria in the early stage of DN, proteinuria progression, and kidney dysfunction over numerous years to decades, resulting in ESRD [116]. Podocytes include a class of uniquely differentiated visceral epithelial cells covering the outside of the GBM, which act as the final protective barrier of the kidney and play an essential role in maintaining the function of GFB. An important event in the development of DN includes the HG-mediated apoptosis of glomerular podocytes, which can result in GFB dysfunction and proteinuria [117]. As discussed in the following subsections, stem cell-derived Exo-miRs released from adipose-derived stem cells (ADSCs), human urinederived stem cells (hUSCs), and BMSCs can effectively inhibit the podocyte injury and thereby ameliorate the GFB dysfunction in DN.

\section{ADSC-EXo-miRs}

There are reports that indicate ADSCs via secreting Exo-miRs, which exert protective effects against the podocyte injury, can improve the glomerular filtration in DN. A recent in vivo study reported that the administration of ADSC-derived exosomes could significantly improve the GFB function through the protective effect against the podocyte apoptosis in DN mice. This effect 
was along with a reduction of the serum creatinine, urine protein, and BUN, as well as the relieved pathological changes of kidney tissues, including the excessive proliferation of GMCs, accumulation of mesangial matrix, and GBM thickness [118]. [It should be noted that the amelioration of mentioned renal pathological changes is not surprising because podocytes can communicate with other glomerular cells, in which podocyte damage may promote proliferation of GMCs [105]]. The in vivo findings were further supported by the in vitro study that showed ADSC-exosomes could effectively suppress the HG-induced apoptosis in mouse podocyte MPC5 [118]. Another study reported that exosomes released by ADSCs contain a high level of miR-26a-5p that is transferred to glomerular podocytes and efficiently ameliorates the pathological symptoms of $\mathrm{DN}$ in diabetic mice [119]. The in vitro study indicated that ADSC-derived Exo-miR-26a-5p could protect HG-induced podocytes from apoptosis and improve their viability by targeting TLR4, downregulating VEGFA, and silencing the NF- $\mathrm{kB}$ pathway [119]. Notably, the thickening of the GBM and the expansion of the mesangial matrix are associated with podocyte apoptosis and autophagic flux suppression. The impaired autophagic function is an indicator of podocyte apoptosis in DN models in vitro and in vivo [120]. The mechanistic target of rapamycin (mTOR) signaling, a key regulator of autophagy, is hyperactivated in $\mathrm{DN}$ and plays a pivotal role in the process of podocyte apoptosis and the decreased rate of glomerular filtration [121]. Of note, ADSC-exosomes were found to improve autophagy flux and decline podocyte apoptosis by suppressing the activation of mTOR signaling in HG-induced MPC5 cells and DN mice [118]. Further study revealed that miR-486 is a key mediator in the process of ADSCExo-mediated alleviation of DN symptoms in vitro and in vivo [118]. Mechanistically, ADSC-Exo-miR-486 was found to directly target and downregulate the expression of Smad1, thereby suppressing the activation of the mTOR pathway, resulting in the promotion of autophagy flux and the inhibition of podocyte apoptosis induced by HG [118].

Furthermore, the HG-mediated podocyte damage can also be characterized by the epithelial-mesenchymal transition (EMT) and the migration resulting in the process of podocyte loss. This process is known as the important causative factor of GFB destruction and proteinuria production, leading to DN development [122]. Notably, ADSCs-exosomes were found to inhibit the HG-induced EMT progression and migration of podocytes through the shuttling miR-215-5p to podocytes. In mechanism, miR-215-5p was shown to mediate such an effect through suppressing the expression of zinc finger E-box-binding homeobox-2 (ZEB2) [123]. This can be supported by other studies that showed miR-215 could suppress cancer cell migration and apoptosis by directly inhibiting ZEB2 expression (124). Mechanistically, ZEB2 can interact with the transcription factor Sp1 to activate the expression of mesenchymal genes, resulting in the promotion of the EMT process and cell migration [125]. ZEB2 can also directly bind to conserved E2 boxes of the E-cadherin promoter to repress E-cadherin expression, thereby accelerating the EMT [126].

In conclusion, ADSCs-exosomes can transport miR26a-5p, miR-486, and miR-215-5p to podocytes where these miRs protect against cell apoptosis and migration and the EMT process, thereby improving glomerular filtration in DN condition. Potentially, such ADSCs-derived Exo-miRs can serve as promising therapeutic candidates for DN treatment in the future.

\section{hUSC-Exo-miRs}

hUSCs have shown significant potential in the treatment of diabetic diseases $[127,128]$. The protective role of hUSCs-derived exosomes against kidney injury in DN has been initially reported by the study that revealed the intravenous injection of hUSC-exosomes in STZ-induced rats could reduce urine volume and urinary microalbumin excretion as well as suppress podocyte apoptosis by inhibiting overexpression of caspase-3 [129]. Further studies indicated that Exo-miR-16-5p secreted by hUSCs could effectively alleviate podocyte apoptosis and enhance podocyte proliferation in the $\mathrm{DN}$ rats and in vitro under $\mathrm{HG}$ condition, mechanistically through inhibiting the expression of VEGFA [130]. VEGFA, a growth factor known for its role in angiogenesis as well as cell permeability and survival, is abnormally expressed in kidney tissues to a wide range of renal diseases [131]. The increased glomerular level of VEGFA in DN mice was found to be attributed to the impact of HG on the VEGFA expression in podocytes [132]. The upregulation of VEGFA in podocytes could cause podocyte apoptosis, abnormality in glomerular selectivity and filtration, and a reduction in renal function in cases of DN [133]. These findings can further support VEGFA-mediated protective effects of hUSCs-Exo-miR-16-5p against DN-induced podocyte injury [130], presenting a new window for future research regarding DN treatment.

\section{BMSC-Exo-miRs}

BMSCs play an important role in the replacement therapy of DN [77], and impaired BMSCs derived from diabetic animals have been found to exert no therapeutic impact on DN [134]. A preclinical study in a mouse model of DN indicated that the treatment with BMSCderived EVs remarkably improved functional parameters, such as the plasma creatinine, BUN, and albumin/ 
creatinine excretion [135]. Importantly, renal fibrosis was significantly inhibited and reverted in EV-treated mice [135]. An association was identified between the anti-fibrotic impact of BMSC-EVs and the downregulation of various pro-fibrotic genes in kidney tissues [135]. A comparative analysis of the miR content of BMSCEVs highlighted some specific patterns of miRs that target predicted pro-fibrotic genes [135]. There is evidence that shows Exo-miR-let-7a implicates the protective role of BMSCs in DN [136]. miR-let-7a targets the ubiquitin-specific peptidase 22 (USP22) that participates in the pathological development of DN via modulating the expression of TGF- $\beta$ [137]. Notably, TGF- $\beta$ induces podocyte apoptosis during glomerulosclerosis [138] and is an important player in renal fibrosis [139]. Of note, the downregulation of miR-let-7a and the overexpression of USP22 have been detected in DN patients [140, 141], renal tissues of DN rats [136], as well as podocytes and mesangial cells under the HG condition $[142,143]$. It was shown that the injection of BMSCs-Exo-miR-let-7a could significantly increase levels of miR-let-7a in renal tissues and thereby improve renal function parameters in DN rats [136]. Indeed, increased Exo-miR-let-7a, through directly targeting and repressing overexpressed USP22 in glomerular cells such as podocytes, could inhibit renal cell apoptosis, which was accompanied with a reduction in serum creatinine, BUN, and blood lipid indices in DN rats [136]. To sum up, BMSCs-exosomes deliver miRlet-7a to renal cells and, whereby, inhibit the cell apoptosis through downregulating USP22, thereby exerting a protective role in DN. This emphasizes potentiality of BMSC-derived Exo-miR-let-7a as the therapeutic tool. However, more studies should be done for taking insights into the underlying molecular mechanisms to develop such BMSC-derived Exo-miR as a novel therapeutic tool for DN treatment.

\section{BMSC-Exo-miRs posing protective effects on renal tubular epithelial cells}

The damage to tubular epithelial cells contributes to interstitial fibrosis in kidney disorders, such as DN. In diabetic animals, treatment with BMSC-derived exosomes has been found to prevent apoptosis and damage of tubular epithelial cells, abolish interstitial fibrosis, and improve kidney function [144, 145] by activating autophagy associated with inhibition of the mTOR signaling pathway [145]. Of note, it was shown that injection of BMSC-derived exosomes in the kidney could improve the histopathological feature of $\mathrm{DN}$ in the form of reduced atrophic alterations, vacuolation, degeneration, and inflammatory cell infiltration of proximal tubule epithelial cells, together with the renal fibrosis [144]. There is a growing body of strong evidence that shows the protective effect of BMSC-derived exosomes on tubular epithelial cells is attributed to their miR content. Notably, it was reported that BMSC-Exo-miR-125b could significantly suppress apoptosis and promote autophagy in HG-treated human embryonic kidney epithelial cells via targeting the TRAF6/Akt axis [146]. Another in vitro study indicated that BMSC-Exo-miR-let7c could be selectively transferred to damaged kidney tubular epithelial cells and suppress the upregulated expression of the ECM molecules, including types $1 \alpha 1$ and IV $\alpha 1$ collagen and $\alpha$-smooth muscle actin ( $\alpha$-SMA), through inhibiting TGF- $\beta 1$ signaling pathway [147]. These effects were found to be companied with the reduction of the ECM accumulation and the amelioration of the fibrosis in a mouse model of renal fibrosis treated with BMSC-ExomiR-let7c [147]. To sum up, exosomes released from BMSCs can protect renal tubular epithelial cells and thus prevent interstitial fibrosis through delivery of miR-125b and miR-let7c.

\section{Circulating Exo-miRs posing potential biomarkers in DN}

The rationale for Exo-miR-based biomarkers

Due to the relatively fast and easy isolation and measurement as well as the high specificity and sensitivity, circulating exosome-based biomarkers such as Exo-miRs have growingly received great attention for their noninvasive diagnostic potentials in various diseases such as DN. Exo-miRs can be detected and isolated from various bodily fluids, particularly urine [148] and serum/plasma [149]. Circulating Exo-miRs possess great characteristics as an ideal source for experimental and clinical biomarkers compared to free-miRs [150]. The biological function is a primary requirement for a candidate biomarker; Exo-miRs are actively secreted and delivered to the distant recipient cells and form an intercellular communication, thereby modulating the function of recipient cells [151]. In the case of specificity, Exo-miRs are selectively packaged and mirror the cellular origin and its (patho)physiological states, thereby enabling recognition of their source and discriminating normal and diseased cells [152], whereas it is a challenge to determine the cell source of a specific circulating free-miR [153]. Moreover, miRs are highly enriched in serum- and urine-derived exosomes, thereby providing higher sensitivity than freemiRs [154]. At variance with free-miRs, Exo-miRs are also in a considerable stable form since the lipid membrane of exosomes protects them against RNase degradation in biological fluids and the storage environment. Exo-miRs are stable during long-term storage and show resistance to multiple freeze-thaw cycles. Notably, urinary Exo-miRs are stable at $4{ }^{\circ} \mathrm{C}$ up to $24 \mathrm{~h}$ for shipping 
before being stored at $-80^{\circ} \mathrm{C}$ and can be stable for one year in urine once stored at $-80^{\circ} \mathrm{C}[155]$.

\section{Urinary Exo-miRs as the potential biomarker in DN}

Urinary exosomes contain a wide array of miRs differentially expressed in DN (Table 2 and Fig. 2). Although profiling of total urine miRs is easier to carry out and less time-consuming with resultant superiority for translation in clinical use, the analysis of urinary Exo-miRs is more accurate since a substantial part of total urinary miRs can originate from other sources, like damaged cells of the urinary tract or plasma miRs passing the GFB, rather than from the kidney tissue [156]. This decreases the relevance of analyzing total urinary miRs for discovering biomarkers in kidney pathophysiology. As illustrated in the following subsections, there is convincing evidence that suggests the distinctive signature of urinary ExomiRs might have the potential as early diagnostic and prognostic biomarkers for DN progression in T1DM or T2DM patients.

\section{Potential urinary Exo-miR biomarkers for the early diagnosis of $D N$}

In a study on T1DM patients, the miR profiling of urinary exosomes indicated a differential expression of urinary Exo-miRs in two firmly matched groups of patients with normo- and microalbuminuria [156]. Of note, patients had a low degree of microalbuminuria and normal renal function, indicating that abnormalities in the expression of urinary Exo-miRs appeared in an early stage of DN [156]. Accordingly, validation of profiling data confirmed that the urinary level of Exo-miR-145 was markedly increased in microalbuminuric patients as compared

Table 2 Potential circulating Exo-miR biomarkers of DN

\begin{tabular}{|c|c|c|c|c|c|}
\hline $\begin{array}{l}\text { miRs } \\
\text { (exosomal level) }\end{array}$ & Species & Type of DN & Cell source & Molecular target & Refs \\
\hline \multicolumn{6}{|l|}{ Urinary exosomal miRs } \\
\hline miR-145 (+) & Human, mouse, cell & Type 1 DN & Mesangial cell & ND & {$[156]$} \\
\hline $\begin{array}{l}\text { miR-15b (+) } \\
\text { miR-34a (+) } \\
\text { miR-636 (+) }\end{array}$ & Human & Type 2 DN & ND & ND & {$[164]$} \\
\hline miR-4534 & Human & Type 2 DN & podocyte & FOXO1 & {$[165]$} \\
\hline miR-320c (+) & Human & Type 2 DN & ND & TSP-1 & {$[167]$} \\
\hline miR-let-7c-5p (+) & Human & Type 2 DN & ND & TGF- $\beta$ & {$[172]$} \\
\hline $\begin{array}{l}\text { miR-362-3p (+) } \\
\text { miR-877-3p (+) } \\
\text { miR-150-5p (+) } \\
\text { miR-15a-5p (-) }\end{array}$ & Human & Type 2 DN & ND & AMPK, p53, mTOR & {$[163]$} \\
\hline $\begin{array}{l}\text { miR-21-5p (+) } \\
\text { miR-30b-5p (-) }\end{array}$ & Human & Type 2 DN & ND & ND & {$[175]$} \\
\hline miR-15b-5p (+) & Human, mouse, cell & Type 2 DN & Mesangial cell & $\mathrm{BCL}-2$ & {$[166]$} \\
\hline $\begin{array}{l}\text { miR-188-5p (+) } \\
\text { miR-150-3p (+) } \\
\text { miR-133a-3p (-) } \\
\text { miR-153-3p (-) }\end{array}$ & Human & Nephrotic-range proteinuria & ND & & {$[111]$} \\
\hline miR-133b (+) miR-342 (+) miR-30a (+) & Human & ND & ND & TGF- $\beta 1$ & {$[158]$} \\
\hline miR-451-5p (+) & Rat & ND & ND & & {$[186]$} \\
\hline miR-483-5p (+) & Mouse & Type 1 and type 2 DN & Tubular cell & MAPK and TIMP2 & {$[187]$} \\
\hline \multicolumn{6}{|l|}{ Serum exosomal miRs } \\
\hline $\begin{array}{l}\text { miR-4449 }(+) \\
\text { miR- } 1246(+) \\
\text { miR-642a-3p (+) } \\
\text { let-7c-5p (+) } \\
\text { miR-1255b-5p (+) let-7i-3p (+) } \\
\text { miR-5010-5p (+) } \\
\text { miR-150-3p (+) }\end{array}$ & Human & ND & ND & $\begin{array}{l}\text { MAPK pathway } \\
\text { TGF- } \beta \text { pathway } \\
\text { Integrin-VEGF pathway } \\
\text { Olfactory Pathway } \\
\text { AP-1and NF-KB network }\end{array}$ & {$[176][178]$} \\
\hline Exo-miR-29 (+) & Human & Type 1 DN & ND & $\begin{array}{l}\text { Serine/threonine-protein } \\
\text { kinase WINK3 gene }\end{array}$ & $(181)$ \\
\hline
\end{tabular}

$(+)$ and (-) show upregulation and downregulation,respectively

Not defined, ND; TSP-1, Thrombospondin 1; VEGF, vascular endothelial growth factor; AP-1, activator protein-1; NF- KB, nuclear factor-KB; MAPK, mitogen-activated protein kinase; TGF- $\beta$, transforming growth factor beta; DN, diabetic nephropathy; the tissue inhibitor of metalloproteinases 2 , TIMP2 


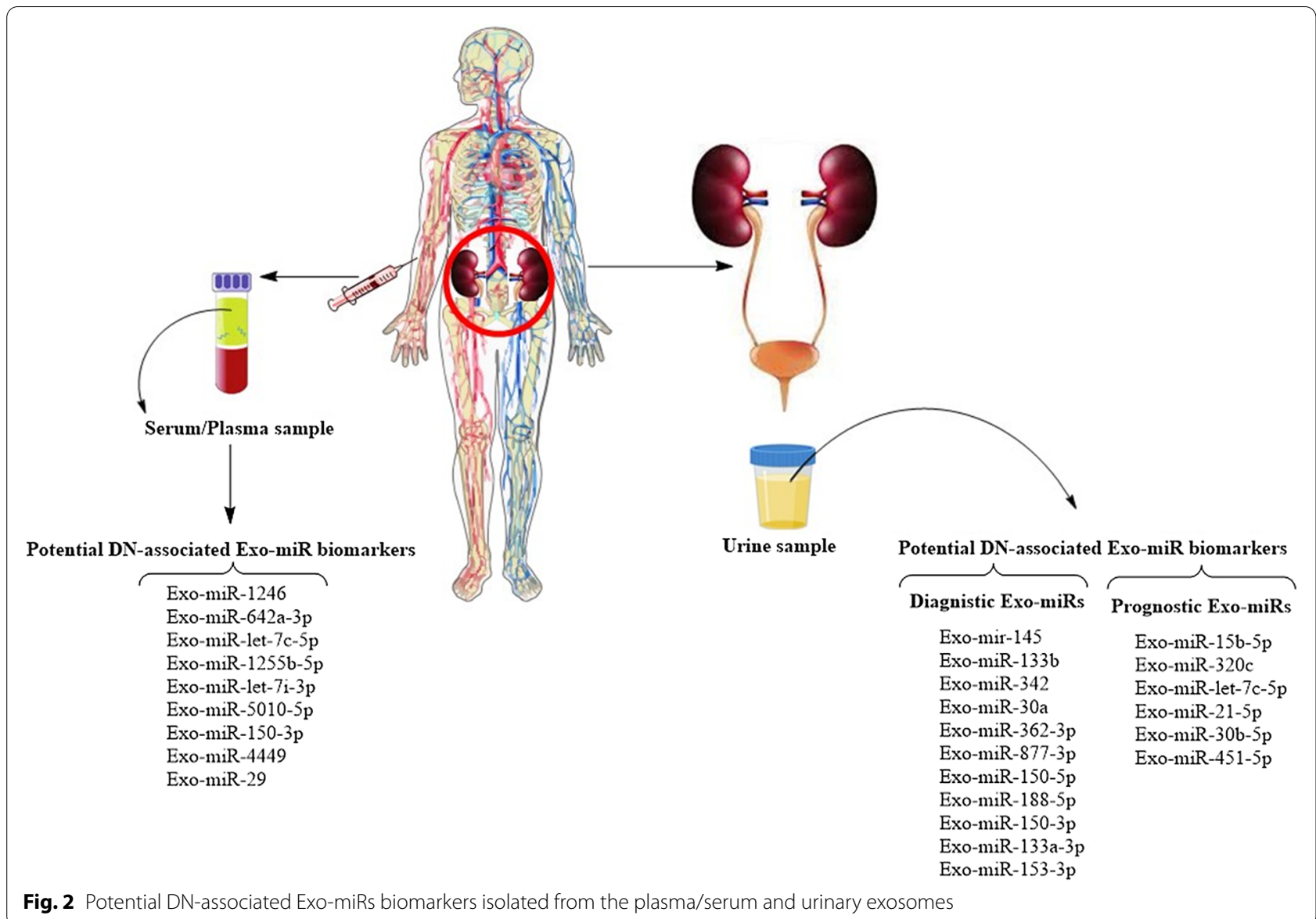

to normoalbuminuric T1DM patients and healthy controls [156]. This result was further supported with a subsequent in vivo study that indicated the miR-145 level was significantly elevated in both urinary exosomes and the glomeruli isolated from mice with early experimental DN [156]. miR-145 is known as a glomerular marker of mesangial cells [157]. The in vitro study [156] revealed that the HG treatment can promote the secretion of miR-145-enriched exosomes by mesangial cells, showing the mesangial cell origin of urinary exosomes carrying an increased level of miR-145 in DN patients. Thus, the elevated level of urinary Exo-mir-145 shows a pathophysiological relevance in the progression of $\mathrm{DN}$ and can provide a candidate biomarker for the early diagnosis of type $1 \mathrm{DN}$.

Besides, there have also been studies that reported potential urinary Exo-miRs for diagnosing early signs of onset or the adverse progression of type $2 \mathrm{DN}$. In a cohort study on T2DM patients [158], urinary Exo-miR133b, Exo-miR-342, and Exo-miR-30a were detected to be highly overexpressed not only in macro- and microalbuminuric patients but also in normoalbuminuric subjects before albuminuria. This suggests the practicality of such urinary Exo-miRs as early molecular indicators prior to the initiation of albuminuria. These urinary Exo-miRs showed a significant positive correlation with renal failure parameters including serum creatinine, eGFR, and UACR. Moreover, Insilco data analysis via "pathway enrichment analysis" identified them as negative regulators of TGF- $\beta 1$ [158]. Supporting is other studies showing involvement of these miRs in diabetic or renal diseases through targeting TGF- $\beta 1$ signaling pathways [138, 159-162]. Taken together, the aforementioned findings indicate that the urinary Exo-miR-133b, Exo-miR-342, and Exo-miR-30a represent potential biomarkers for early diagnosis and risk stratification of type 2 DN. Potential urinary Exo-miRs for early diagnosis of type $2 \mathrm{DN}$ were also reported by another study that showed the increased expression of three urinary ExomiRs (miR-362-3p, miR-877-3p, and miR-150-5p) and the reduced expression of one (miR-15a-5p) in incipient T2DM patients with macroalbuminuria compared to those without macroalbuminuria [163]. Of note, these miRs were predicted to regulate pathways involved in DN processes, including AMP-activated protein kinase (AMPK), mTOR, and the p53 (apoptosis-induced nuclear 
transcription factor) pathways [163]. Another study on T2DM patients revealed the significant increase in urinary levels of a panel of Exo-miRs including Exo-miR15b, Exo-miR-34a, and Exo-miR-636 in both DN and normoalbuminuric patients [164]. Notably, dysregulation of this panel of urinary Exo-miRs indicated a significant correlation with age, body mass index (BMI), HBA1c, hypertension, serum creatinine, and UACR [164]. These Exo-miRs were found to contribute to the DN pathogenesis through targeting critical pathways affected in $\mathrm{DN}$, such as glucose metabolism, cell proliferation and apoptosis, cytokine release and growth factor signaling, as well as nephrogenesis and renal fibrosis [164]. Importantly, the diagnostic value of the urinary Exo-miR-based panel was strongly higher than that of the individual miR, reaching 100\% sensitivity in diagnosing DN [164]. Thus, this urinary Exo-miR panel was suggested as a potential biomarker with high sensitivity and specificity in the early diagnosis of DN [164]. In the other study, profiling of urinary Exo-miRs indicated that miR-4534 was highly upregulated in DN patients compared to T2DM patients and healthy volunteers [165]. Importantly, the urinary level of Exo-miR-4534 showed a firm correlation with microalbuminuria in DN patients, while there was no correlation in the T2DM patients [165]. This suggests a possible role of Exo-miR-4534 in the early formation of microalbuminuria. The functional analysis indicated that the FOXO1 signaling pathway is a target of miR4534 in DN. miR-4534 was found to involve in the DN progression by activating the FOXO/BNIP3/Atg12-mediated inflammatory pathway and worsening the podocyte damage [165]. FOXO1 has a role in the regulation of autophagy. It suppresses the expression of Atg14 to destroy the autophagy-lysosomal fusion, thereby inducing autophagy and apoptosis leading to vascular complications in diabetes [165].

Significantly, nephrotic-range proteinuria presents the most deleterious figure of proteinuria in diabetic patients. The analysis of urinary Exo-miR profile in nephrotic, renal biopsy-proven DN patients revealed the highest upregulation with miR-188-5p and miR-150-3p as well as the highest downregulation with miR-133a-3p and miR-153-3p. The functional analysis and the targetgene prediction of these miRs verified that they contribute to novel and known pathways of DN, supporting their pathologic role and potential as the biomarker in DN patients with nephrotic-range proteinuria [111].

\section{Potential urinary Exo-miR biomarkers for the prognosis/ prediction of $D N$}

A recent study [166] indicated that both diabetic mice and T2DM patients with microalbuminuria had higher urinary levels of Exo-miR-15b-5p when compared with normoalbuminuric patients and healthy subjects. Notably, a mean follow-up period of 2.4 years indicated that urinary levels of Exo-miR-15b-5p are negatively correlated with eGFR and positively correlated with UACR and a rapid decline in renal function in T2DM patients. The in vitro study revealed that miR-15b-5p participates in the HG-mediated kidney injury by inducing mesangial cell apoptosis via targeting BCL-2 [166]. Moreover, in two independent cohort studies on T2DM patients [167], the expression profiling of urinary Exo-miRs indicated a differential signature of miRs in patients with microalbuminuria (stages 3 and $4 \mathrm{DN}$ ) compared to normoalbuminuric patients. Notably, the miR profile analysis showed a robust upregulation of miR-320c in urinary exosomes of patients with microalbuminuria [167]. Importantly, urinary levels of Exo-miR-320c were found to have negative and positive graded correlations with eGFR and UACR, respectively [167]. The increased level of urinary Exo-miR-320c might be a compensatory response to the over-activated TGF- $\beta$ signaling pathway during DN progression. Indeed, miR-320c downregulates the TGF- $\beta$ signaling via targeting thrombospondin 1 (TSP-1) [167] that is a key activator of TGF- $\beta$ in renal fibrosis [168, $169]$ and shows an elevated expression in the glomeruli of DN patients [170, 171]. Another study on T2DM patients [172] showed that the level of miR-let-7c-5p was significantly elevated in urinary exosomes of DN subjects compared with patients without nephropathy as well as healthy controls. The urinary levels of Exo-miRlet-7c-5p also indicated a significant correlation with the eGFR and DN progression [172]. It can be further supported by other studies that reported the miR-let-7 family members (let-7b and let-7c) play functional roles in renal fibrosis $[173,174]$ and attenuate the renal fibrosis in DM through downregulating the TGF- $\beta$ pathway [147]. Thus, it is likely that the increased level of urinary Exolet-7c-5p is due to a physiological response to limit the renal fibrosis in DN. Another study also reported a high upregulation of miR-21-5p and a high downregulation of miR-30b-5p in urinary exosomes isolated from T2DM patients with DN and the poor renal function, suggesting them as promising predictors of the progression of early-stage DN to the renal failure [175]. In sum, these findings suggest urinary Exo-miR-15b-5p, Exo-miR-320c, Exo-let-7c-5p, Exo-miR-21-5p, and Exo-miR-30b-5p as the potential biomarkers for prognosing the severity and the adverse progression of the renal injury in type $2 \mathrm{DN}$.

\section{Serum Exo-miRs as potential biomarkers in DN}

In addition to the urine Exo-miRs analysis, reports regarding the analysis of serum Exo-miRs exist as well. Evaluating the profile of serum Exo-miRs in healthy volunteers and diabetic patients with and 
without nephropathy indicated that, among differentially expressed Exo-miRs, eight miRs (miR-1246, miR-642a-3p, let-7c-5p, miR-1255b-5p, let-7i-3p, miR5010-5p, miR-150-3p, and miR-4449) were DN-specific and their levels were significantly and uniquely increased in circulating exosomes [176]. Importantly, serum levels of these Exo-miRs were strongly correlated with the degree of albuminuria [176]. Notably, according to pathway analysis using miRSystem and DIANA-miRPath [176], these Exo-miRs were predicted to involve in the pathways and molecular targets previously reported to play a distinct pathogenic role in the progression of DN. These include the mitogen-activated protein kinase (MAPK) signaling pathway, the integrin-VEGF axis [177], the olfactory signaling pathway, and the activator protein-1 (AP-1) and nuclear factor- $\mathrm{kB}$ (NF- $\mathrm{kB}$ ) transcription factor network [176]. Of note, among these miRs, miR-4449 was highly overexpressed in DN patients compared to patients without DN [176]. It is further supported by a recent study that showed miR-4449 is enriched in the serum exosomes of DN patients [178]. The functional analysis indicated that the overexpression of miR-4449 promotes inflammation, oxidative stress, and pyroptosis [178]. The other studies have also shown a significant correlation between the miR-4449 and the degree of albuminuria and suggested its potential as a novel biomarker for DN $[179,180]$. These findings suggest serum Exo-miR-4449 as the promising biomarker candidate for the diagnosis/prognosis of DN.

Further, a cross-sectional case-control study including children and adolescents with T1DM [181] indicated that serum levels of Exo-miR-29 were significantly increased in subjects with microalbuminuria compared to subjects without microalbuminuria and healthy controls [181]. Exo-miR-29 was predicted to target the serine/threonineprotein kinase WINK3 gene that participates in glucose transporter mechanisms in the insulin signaling pathway as well as the beta-cell signaling and survival [181]. It was further supported by "enriched pathway analysis" that showed Exo-miR-29 targets numerous molecular and signaling pathways included in the insulin signaling pathway as well as the renal and nephron epithelium development [181]. This is in agreement with other studies that reported the regulatory role of miR-29 in the glucose homeostasis and the insulin action [182] and also showed increased serum levels of this miR in T1DM children and adult T2DM patients [183-185], which was associated with pathogenesis and progression of DN [183]. Notably, the regression analysis after adjustment of age, sex, BMI, disease duration, and lipid profile showed a strong association between the serum level of Exo-miR-29 with T1DM and persistent microalbuminuria [181]. Among patients with persistent microalbuminuria, the level of
UACR was significantly higher in subjects with miR-29 overexpression than in those who did not exhibit overexpression [181]. Evaluating the differentiation between T1DM patients with and without persistent microalbuminuria confirmed that circulating Exo-miR-29 might represent a potential blood-based biomarker for early diagnosis of the DN in pediatric T1DM patients [181].

\section{Novel Exo-miR biomarkers based on the animal studies}

An in vivo study on STZ-induced diabetic rats indicated that the level of urinary Exo-miR-451-5p was highly increased, by $>1000$-fold, early on during the course of diabetes, before the renal damage. Notably, the increase in urinary levels of Exo-miR-451-5p was found to be a more sensitive predictor of DN when compared to albumin excretion [186]. This can support the potential usefulness of urinary Exo-miR-451-5p as a sensitive prognostic biomarker, instead of albumin excretion levels, to serially monitor the early renal damage in diabetic patients. However, further investigations are warranted to address this claim in human subjects.

Another in vivo study showed that the miR-483-5p expression was reduced in kidney tissues of type 1 and type 2 diabetic mice and HG-stimulated tubular epithelial cells, while it was increased in the urinary exosomes [187]. miR-483-5p was found to inhibit expressions of fibrosis-related genes in vitro and alleviate the renal interstitial fibrosis in vivo, through targeting and suppressing MAPK and the tissue inhibitor of metalloproteinases 2 (TIMP2) in renal tubular epithelial cells under HG conditions [187]. Importantly, HNRNPA1-mediated exosomal sorting transported cellular miR-483-5p out of tubular epithelial cells into the urine, thus reducing the inhibitory impact of cellular miR-483-5p on MAPK1 and TIMP2 mRNAs, and ultimately boosting the ECM accumulation and the progression of DN-induced renal interstitial fibrosis [187]. Thus, Exo-miR-483-5p has a valuable potential to be further assessed as a biomarker for the early diagnosis of renal fibrosis in $\mathrm{DN}$.

\section{Conclusions}

Despite numerous years of attempts, effective therapeutic approaches and fruitful diagnosis/prognosis biomarkers for DN remain still elusive. Endocrinologists and nephrologists are constantly searching for new therapeutic tools as well as for novel strategies to enhance their knowledge for rapid and accurate diagnosing of kidney disorders resulting from diabetes.

The present review of preclinical and clinical studies can conclude that stem cell-derived Exo-miRs provide promising therapeutic tools, while the differential expression of circulating Exo-miRs represents emerging biomarkers for DN. Stem cell-derived exosomes have 
shown beneficial effects in DN by transferring renoprotective miRs to injured renal cells. BMSC-secreted exosomes have been found to deliver renoprotective miRs to injured renal cells including podocytes (ExomiR-let-7a), mesangial cells (Exo-miR-222), and tubular cells (Exo-miR-125b and Exo-miR-let7c). Moreover, exosomes secreted by adMSCs could deliver renoprotective miR-125a to injured mesangial cells, while renoprotective Exo-miRs secreted by ADSCs (miR-26a-5p, miR-486, and miR-215-5p), and hUSCs (Exo-miR16-5p) are transferred to injured podocytes. Besides, urinary Exo-mir-145 in T1DM, urinary Exo-miR-133b, Exo-miR-342, Exo-miR-30a, Exo-miR-15b, Exo-miR34a, and Exo-miR-636, and Exo-miR-4534 in T2DM, and urinary Exo-miR-188-5p, Exo-miR-150-3p, ExomiR-133a-3p, and Exo-miR-153-3p in diabetic patients with nephrotic-range proteinuria provide candidate promising biomarkers for the early diagnosis of DN. In addition, urinary Exo-miR-15b-5p, Exo-miR-320c, Exolet-7c-5p, Exo-miR-21-5p, and Exo-miR-30b-5p have been found as potential biomarkers for prognosing the severity and the adverse progression of renal injury in type 2 DN. Urinary Exo-miR-451-5p shows the potential usefulness as a sensitive prognostic biomarker, instead of albumin excretion levels, to serially monitor the early renal damage in diabetes. On the other hand, the expression of a panel of eight serum Exo-miRs (miR- 1246, miR-642a-3p, let-7c-5p, miR-1255b-5p, let-7i-3p, miR-5010-5p, miR-150-3p, and miR-4449) is DN-specific and provides the promising biomarker candidate for the diagnosis of DN. Further, Exo-miR-29 was found as a potential serum-based biomarker for the early diagnosis of $\mathrm{DN}$ in pediatric T1DM patients.

The aforementioned conclusions of the present review article indicate that Exo-miRs donate great promise for the future progression in DN treatments, permitting more patients suffering from $\mathrm{DN}$ to benefit, more likely in the near future.

\footnotetext{
Abbreviations

DN: Diabetic nephropathy; ESRD: End-stage renal disease; DM: Diabetes, mellitus; T1DM: Type I DM; T2DM: Type II DM; ECM: Extracellular matrix; GBM: Glomerular basement membrane; BUN: Blood urea nitrogen; eGFR: Estimated glomerular filtration rate; UACR: Urine albumin-to-creatinine ratio; RAAS: Renin-angiotensin-aldosterone system; GLP-1: Glucagon-like peptide-1; SGLT2: Sodium-glucose co-transporter 2; miRs: MicroRNAs; Exo-miRs: Exosomal miRs; adMSCs: Adipose-derived mesenchymal stem cells; ADSCs: Adipose-derived stem cells; hUSCs: Human urine-derived stem cells; BMSCs: Bone marrow mesenchymal stem cells; GMCs: Glomerular mesangial cells; HG: High glucose; IL-6: Interleukin-6; HDAC1: Histone deacetylase 1; ET-1: Endothelin-1; GFB: Glomerular filtration barrier; mTOR: Mechanistic target of rapamycin; EMT: Epithelial-mesenchymal transition; ZEB2: Zinc finger E-boxbinding homeobox-2; VEGFA: Vascular endothelial growth factor A; USP22: Ubiquitin-specific peptidase 22; TGF- $\beta$ : Transforming growth factor beta; MAPK: Mitogen-activated protein kinase; AP-1: Activator protein-1; NF-KB: Nuclear factor-kB; BMI: Body mass index.
}

Acknowledgements Not applicable.

\section{Authors' contributions}

SS and HW contributed to the conception and design of the work. LP and $\mathrm{YC}$ were contributors in the database search and preparing the manuscript. SS and HW read and approved the final manuscript. All authors read and approved the final manuscript.

\section{Funding}

Not applicable.

\section{Declarations}

Ethics approval and consent to participate

Not applicable.

Consent for publication

Not applicable.

Availability of data and materials

Not applicable.

\section{Competing interests}

The authors declare that they have no competing interests.

\section{Author details}

${ }^{1}$ Department of Nephrology, Sichuan Academy of Medical Science and Sichuan Provincial People's Hospital, Chengdu 610072, China. ${ }^{2}$ Department of Cardiology, Sichuan Academy of Medical Science and Sichuan Provincial People's Hospital, Chengdu 610072, China. ${ }^{3}$ Department of Pulmonary and Critical Care Medicine, The First Affiliated Hospital of Kunming Medical University, Kunming 650032, China.

Received: 14 October 2021 Accepted: 20 December 2021

Published online: 24 January 2022

\section{References}

1. DeFronzo RA, Reeves WB, Awad AS. Pathophysiology of diabetic kidney disease: impact of SGLT2 inhibitors. Nat Rev Nephrol. 2021;17(5):319-34.

2. Alicic RZ, Rooney MT, Tuttle KR. Diabetic kidney disease: challenges, progress, and possibilities. Clin J Am Soc Nephrol. 2017;12(12):2032-45.

3. Abbasi F, Moosaie F, Khaloo P, Firouzabadi FD, Abhari SMF, Atainia B, et al. Neutrophil gelatinase-associated lipocalin and retinol-binding protein-4 as biomarkers for diabetic kidney disease. Kidney Blood Press Res. 2020;45(2):222-32.

4. Campion CG, Sanchez-Ferras O, Batchu SN. Potential role of serum and urinary biomarkers in diagnosis and prognosis of diabetic nephropathy. Can J Kidney Health Dis. 2017:4:2054358117705371.

5. Bucala R, Vlassara H. Advanced glycosylation end products in diabetic renal and vascular disease. Am J Kidney Dis. 1995;26(6):875-88.

6. Zhou G, Li C, Cai L. Advanced glycation end-products induce connective tissue growth factor-mediated renal fibrosis predominantly through transforming growth factor $\beta$-independent pathway. Am J Pathol. 2004:165(6):2033-43.

7. D'agati V, Schmidt AM. RAGE and the pathogenesis of chronic kidney disease. Nat Rev Nephrol. 2010;6(6):352-60.

8. Navarro-González JF, Mora-Fernández C, Muros de Fuentes M, GarcíaPérez J. Inflammatory molecules and pathways in the pathogenesis of diabetic nephropathy. Nat Rev Nephrol. 2011;7(6):327-40. PubMed PMID: 21537349. Epub 2011/05/04. eng.

9. Pavkov ME, Knowler WC, Lemley KV, Mason CC, Myers BD, Nelson RG. Early renal function decline in type 2 diabetes. Clin J Am Soc Nephrol. 2012;7(1):78-84.

10. Glassock RJ. Debate: CON position. Should microalbuminuria ever be considered as a renal endpoint in any clinical trial? Am J Nephrol. 2010;31(5):462. 
11. Muskiet MH, Wheeler DC, Heerspink HJ. New pharmacological strategies for protecting kidney function in type 2 diabetes. Lancet Diabetes Endocrinol. 2019;7(5):397-412.

12. Alter ML, Kretschmer A, Von Websky K, Tsuprykov G, Reichetzeder C, Simon A, et al. Early urinary and plasma biomarkers for experimental diabetic nephropathy. Clin Lab. 2012;58(7):659.

13. Chang J-H, Paik S-Y, Mao L, Eisner W, Flannery PJ, Wang L, et al. Diabetic kidney disease in FVB/NJ Akita mice: temporal pattern of kidney injury and urinary nephrin excretion. PLoS ONE. 2012;7(4):e33942.

14. Wada Y, Abe M, Moritani $\mathrm{H}$, Mitori H, Kondo M, Tanaka-Amino K, et al. Potential of urinary nephrin as a biomarker reflecting podocyte dysfunction in various kidney disease models. Exp Biol Med. 2016;241(16):1865-76.

15. Gewin L, Zent R, Pozzi A. Progression of chronic kidney disease: too much cellular talk causes damage. Kidney Int. 2017;91 (3):552-60.

16. Wang G, Lai FM-M, Lai K-B, Chow K-M, Li K-TP, Szeto C-C. Messenger RNA expression of podocyte-associated molecules in the urinary sediment of patients with diabetic nephropathy. Nephron Clin Pract. 2007;106(4):C169-79.

17. do Nascimento JF, Canani LH, Gerchman F, Rodrigues PG, Joelsons G, dos Santos M, et al. Messenger RNA levels of podocyte-associated proteins in subjects with different degrees of glucose tolerance with or without nephropathy. BMC Nephrol. 2013;14(1):1-10.

18. Ng DP, Tai B-C, Tan E, Leong H, Nurbaya S, Lim X-L, et al. Nephrinuria associates with multiple renal traits in type 2 diabetes. Nephrol Dial Transplant. 2011;26(8):2508-14.

19. Hara M, Yamagata K, Tomino Y, Saito A, Hirayama Y, Ogasawara S, et al. Urinary podocalyxin is an early marker for podocyte injury in patients with diabetes: establishment of a highly sensitive ELISA to detect urinary podocalyxin. Diabetologia. 2012;55(11):2913-9.

20. Jim B, Ghanta M, Qipo A, Fan Y, Chuang PY, Cohen HW, et al. Dysregulated nephrin in diabetic nephropathy of type 2 diabetes: a cross sectional study. PLoS ONE. 2012;7(5):e36041.

21. Donate-Correa J, Martín-Núñez E, Muros-de-Fuentes M, MoraFernández C, Navarro-González JF. Inflammatory cytokines in diabetic nephropathy. J Diabetes Res. 2015;2015:1.

22. Chang AS, Hathaway CK, Smithies O, Kakoki M. Transforming growth factor- $\beta 1$ and diabetic nephropathy. Am J Physiol-Renal Physiol. 2016;310(8):F689-96.

23. Mou X, Zhou D-Y, Zhou D-Y, Ma J-R, Liu Y-H, Chen H-P, et al. Serum TGF$\beta 1$ as a biomarker for type 2 diabetic nephropathy: a meta-analysis of randomized controlled trials. PLoS ONE. 2016;11(2):e0149513.

24. Navarro JF, Mora C, Muros M, García J. Urinary tumour necrosis factor-a excretion independently correlates with clinical markers of glomerular and tubulointerstitial injury in type 2 diabetic patients. Nephrol Dial Transplant. 2006;21(12):3428-34.

25. Pickup JC, Chusney GD, Thomas SM, Burt D. Plasma interleukin-6, tumour necrosis factor a and blood cytokine production in type 2 diabetes. Life Sci. 2000;67(3):291-300.

26. Wu C-C, Chen J-S, Lu K-C, Chen C-C, Lin S-H, Chu P, et al. Aberrant cytokines/chemokines production correlate with proteinuria in patients with overt diabetic nephropathy. Clin Chim Acta. 2010;41 1(9-10):700-4.

27. Niewczas MA, Ficociello LH, Johnson AC, Walker W, Rosolowsky ET, Roshan B, et al. Serum concentrations of markers of TNFa and Fasmediated pathways and renal function in nonproteinuric patients with type 1 diabetes. Clin J Am Soc Nephrol. 2009;4(1):62-70.

28. Gohda T, Niewczas MA, Ficociello LH, Walker WH, Skupien J, Rosetti F, et al. Circulating TNF receptors 1 and 2 predict stage 3 CKD in type 1 diabetes. J Am Soc Nephrol. 2012;23(3):516-24.

29. Niewczas MA, Gohda T, Skupien J, Smiles AM, Walker WH, Rosetti F, et al. Circulating TNF receptors 1 and 2 predict ESRD in type 2 diabetes. J Am Soc Nephrol. 2012;23(3):507-15.

30. Venkatachalam MA, Weinberg JM, Kriz W, Bidani AK. Failed tubule recovery, AKI-CKD transition, and kidney disease progression. J Am Soc Nephrol. 2015;26(8):1765-76.

31. Devarajan P. Neutrophil gelatinase-associated lipocalin (NGAL): a new marker of kidney disease. Scand J Clin Lab Invest. 2008;68(sup241):89-94.

32. Ning M, Mao X, Niu Y, Tang B, Shen H. Usefulness and limitations of neutrophil gelatinase-associated lipocalin in the assessment of kidney diseases. J Lab Precis Med. 2018;3(1):1.
33. Bolignano D, Donato V, Coppolino G, Campo S, Buemi A, Lacquaniti A, et al. Neutrophil gelatinase-associated lipocalin (NGAL) as a marker of kidney damage. Am J Kidney Dis. 2008;52(3):595-605.

34. Mishra J, Dent C, Tarabishi R, Mitsnefes MM, Ma Q, Kelly C, et al. Neutrophil gelatinase-associated lipocalin (NGAL) as a biomarker for acute renal injury after cardiac surgery. The Lancet. 2005;365(9466):1231-8.

35. Nauta FL, Boertien WE, Bakker SJ, Van Goor H, Van Oeveren W, De Jong $P E$, et al. Glomerular and tubular damage markers are elevated in patients with diabetes. Diabetes Care. 2011;34(4):975-81.

36. Kapoula GV, Kontou PI, Bagos PG. Diagnostic accuracy of neutrophil gelatinase-associated lipocalin for predicting early diabetic nephropathy in patients with type 1 and type 2 diabetes mellitus: a systematic review and meta-analysis. J Appl Lab Med. 2019;4(1):78-94.

37. Looker HC, Colombo M, Hess S, Brosnan MJ, Farran B, Dalton RN, et al. Biomarkers of rapid chronic kidney disease progression in type 2 diabetes. Kidney Int. 2015;88(4):888-96.

38. Lewis EJ, Hunsicker LG, Bain RP, Rohde RD. The effect of angiotensinconverting-enzyme inhibition on diabetic nephropathy. N Engl J Med. 1993;329(20):1456-62.

39. Lewis EJ, Hunsicker LG, Clarke WR, Berl T, Pohl MA, Lewis JB, et al. Renoprotective effect of the angiotensin-receptor antagonist irbesartan in patients with nephropathy due to type 2 diabetes. N Engl J Med. 2001;345(12):851-60.

40. Parving H-H, Lehnert $\mathrm{H}$, Bröchner-Mortensen J, Gomis R, Andersen $\mathrm{S}$, Arner P. The effect of irbesartan on the development of diabetic nephropathy in patients with type 2 diabetes. $N$ Engl J Med. 2001:345(12):870-8.

41. Brenner BM, Cooper ME, De Zeeuw D, Keane WF, Mitch WE, Parving $\mathrm{H}-\mathrm{H}$, et al. Effects of losartan on renal and cardiovascular outcomes in patients with type 2 diabetes and nephropathy. N Engl J Med. 2001;345(12):861-9.

42. Anders H-J, Davis JM, Thurau K. Nephron protection in diabetic kidney disease. N Engl J Med. 2016;375(21):2096-8.

43. Palevsky PM, Zhang JH, Seliger SL, Emanuele N, Fried LF. Incidence, severity, and outcomes of AKI associated with dual renin-angiotensin system blockade. Clin J Am Soc Nephrol. 2016;1 1(11):1944-53.

44. Fried LF, Emanuele N, Zhang JH, Brophy M, Conner TA, Duckworth W, et al. Combined angiotensin inhibition for the treatment of diabetic nephropathy. N Engl J Med. 2013;369(20):1892-903.

45. Mann JF, Schmieder RE, McQueen M, Dyal L, Schumacher H, Pogue J, et al. Renal outcomes with telmisartan, ramipril, or both, in people at high vascular risk (the ONTARGET study): a multicentre, randomised, double-blind, controlled trial. Lancet. 2008;372(9638):547-53.

46. Bakris GL, Agarwal R, Anker SD, Pitt B, Ruilope LM, Rossing P, et al. Effect of finerenone on chronic kidney disease outcomes in type 2 diabetes. N Engl J Med. 2020;383(23):2219-29.

47. Ito S, Shikata K, Nangaku M, Okuda Y, Sawanobori T. Efficacy and safety of esaxerenone (CS-3150) for the treatment of type 2 diabetes with microalbuminuria: a randomized, double-blind, placebo-controlled, phase II trial. Clin J Am Soc Nephrol. 2019;14(8):1161-72.

48. Bakris GL, Agarwal R, Chan JC, Cooper ME, Gansevoort RT, Haller H, et al. Effect of finerenone on albuminuria in patients with diabetic nephropathy: a randomized clinical trial. JAMA. 2015;314(9):884-94.

49. Wanner C, Inzucchi SE, Lachin JM, Fitchett D, von Eynatten M, Mattheus $M$, et al. Empagliflozin and progression of kidney disease in type 2 diabetes. N Engl J Med. 2016;375(4):323-34.

50. Neal B, Perkovic V, Mahaffey KW, De Zeeuw D, Fulcher G, Erondu N, et al. Canagliflozin and cardiovascular and renal events in type 2 diabetes. N Engl J Med. 2017;377(7):644-57.

51. Wiviott SD, Raz I, Bonaca MP, Mosenzon O, Kato ET, Cahn A, et al. Dapagliflozin and cardiovascular outcomes in type 2 diabetes. N Engl J Med. 2019:380(4):347-57.

52. Heerspink HJ, Stefánsson BV, Correa-Rotter R, Chertow GM, Greene T, Hou F-F, et al. Dapagliflozin in patients with chronic kidney disease. N Engl J Med. 2020;383(15):1436-46.

53. Perkovic V, Jardine MJ, Neal B, Bompoint S, Heerspink HJ, Charytan $\mathrm{DM}$, et al. Canagliflozin and renal outcomes in type 2 diabetes and nephropathy. N Engl J Med. 2019;380(24):2295-306.

54. Gerstein HC, Colhoun HM, Dagenais GR, Diaz R, Lakshmanan M, Pais P, et al. Dulaglutide and renal outcomes in type 2 diabetes: an exploratory 
analysis of the REWIND randomised, placebo-controlled trial. The Lancet. 2019;394(10193):131-8.

55. Muskiet MH, Tonneijck L, Huang Y, Liu M, Saremi A, Heerspink HJ, et al. Lixisenatide and renal outcomes in patients with type 2 diabetes and acute coronary syndrome: an exploratory analysis of the ELIXA randomised, placebo-controlled trial. Lancet Diabetes Endocrinol. 2018;6(11):859-69.

56. Tuttle KR, Lakshmanan MC, Rayner B, Busch RS, Zimmermann AG, Woodward DB, et al. Dulaglutide versus insulin glargine in patients with type 2 diabetes and moderate-to-severe chronic kidney disease (AWARD-7): a multicentre, open-label, randomised trial. Lancet Diabetes Endocrinol. 2018;6(8):605-17.

57. Lacava V, Pellicanò V, Ferrajolo C, Cernaro V, Visconti L, Conti G, et al. Novel avenues for treating diabetic nephropathy: new investigational drugs. Expert Opin Investig Drugs. 2017;26(4):445-62.

58. Tesch GH, Ma FY, Han Y, Liles JT, Breckenridge DG, Nikolic-Paterson DJ. ASK1 inhibitor halts progression of diabetic nephropathy in Nos3deficient mice. Diabetes. 2015;64(11):3903-13.

59. Navarro-González JF, Mora-Fernández C, de Fuentes MM, Chahin J, Méndez ML, Gallego $E$, et al. Effect of pentoxifylline on renal function and urinary albumin excretion in patients with diabetic kidney disease: the PREDIAN trial. J Am Soc Nephrol. 2015;26(1):220-9.

60. Leyva-Jimenez R, Rodriguez-Orozco AR, Ortega-Pierres LE, Ramirez-Enriquez J, Gomez-Garcia A, Alvarez-Aguilar C. Effect of pentoxifylline on the evolution of diabetic nephropathy. Med Clin. 2009;132(20):772-8.

61. Sabounjian L, Graham P, Wu L, Braman V, Cheng C, Liu J, et al. A Firstin-Patient, Multicenter, Double-Blind, 2-Arm, Placebo-Controlled, Randomized Safety and Tolerability Study of a Novel Oral Drug Candidate, CTP-499, in Chronic Kidney Disease. Clin Pharmacol Drug Dev. 2016:5(4):314-25

62. Scheele W, Diamond S, Gale J, Clerin V, Tamimi N, Le V, et al. Phosphodiesterase type 5 inhibition reduces albuminuria in subjects with overt diabetic nephropathy. J Am Soc Nephrol. 2016;27(11):3459-68.

63. Sullivan T, Miao Z, Dairaghi DJ, Krasinski A, Wang Y, Zhao BN, et al. CCR2 antagonist CCX140-B provides renal and glycemic benefits in diabetic transgenic human CCR2 knockin mice. Am J Physiol-Renal Physiol. 2013;305(9):F1288-97.

64. Boels MG, Koudijs A, Avramut MC, Sol WM, Wang G, van OeverenRietdijk AM, et al. Systemic monocyte chemotactic protein-1 inhibition modifies renal macrophages and restores glomerular endothelial glycocalyx and barrier function in diabetic nephropathy. Am J Pathol. 2017;187(11):2430-40.

65. de Zeeuw D, Bekker P, Henkel E, Hasslacher C, Gouni-Berthold I, Mehling $\mathrm{H}$, et al. The effect of CCR2 inhibitor CCX140-B on residual albuminuria in patients with type 2 diabetes and nephropathy: a randomised trial. Lancet Diabetes Endocrinol. 2015;3(9):687-96.

66. Menne J, Eulberg D, Beyer D, Baumann M, Saudek F, Valkusz Z, et al. CC motif-ligand 2 inhibition with emapticap pegol (NOX-E36) in type 2 diabetic patients with albuminuria. Nephrol Dial Transplant. 2017;32(2):307-15.

67. Barutta F, Bruno G, Mastrocola R, Bellini S, Gruden G. The role of cannabinoid signaling in acute and chronic kidney diseases. Kidney Int. 2018;94(2):252-8.

68. Barutta F, Bellini S, Mastrocola R, Gambino R, Piscitelli F, di Marzo V, et al. Reversal of albuminuria by combined AM6545 and perindopril therapy in experimental diabetic nephropathy. Br J Pharmacol. 2018;175(23):4371-85.

69. Barutta F, Grimaldi S, Gambino R, Vemuri K, Makriyannis A, Annaratone $L$, et al. Dual therapy targeting the endocannabinoid system prevents experimental diabetic nephropathy. Nephrol Dial Transplant. 2017;32(10):1655-65.

70. Kohan DE, Barton M. Endothelin and endothelin antagonists in chronic kidney disease. Kidney Int. 2014;86(5):896-904.

71. Sasser JM, Sullivan JC, Hobbs JL, Yamamoto T, Pollock DM, Carmines $\mathrm{PK}$, et al. Endothelin A receptor blockade reduces diabetic renal injury via an anti-inflammatory mechanism. J Am Soc Nephrol. 2007;18(1):143-54.

72. Benigni A, Colosio V, Brena C, Bruzzi I, Bertani T, Remuzzi G. Unselective inhibition of endothelin receptors reduces renal dysfunction in experimental diabetes. Diabetes. 1998;47(3):450-6.
73. Boels MG, Avramut MC, Koudijs A, Dane MJ, Lee DH, Van Der Vlag J, et al. Atrasentan reduces albuminuria by restoring the glomerular endothelial glycocalyx barrier in diabetic nephropathy. Diabetes. 2016;65(8):2429-39.

74. Watson A, Li J, Schumacher C, De Gasparo M, Feng B, Thomas M, et al. The endothelin receptor antagonist avosentan ameliorates nephropathy and atherosclerosis in diabetic apolipoprotein E knockout mice. Diabetologia. 2010;53(1):192-203.

75. Heerspink HJ, Parving H-H, Andress DL, Bakris G, Correa-Rotter R, Hou $\mathrm{F}-\mathrm{F}$, et al. Atrasentan and renal events in patients with type 2 diabetes and chronic kidney disease (SONAR): a double-blind, randomised, placebo-controlled trial. Lancet. 2019;393(10184):1937-47.

76. An X, Liao G, Chen Y, Luo A, Liu J, Yuan Y, et al. Intervention for early diabetic nephropathy by mesenchymal stem cells in a preclinical nonhuman primate model. Stem Cell Res Ther. 2019;10(1):1-16.

77. Sun J, Zhao F, Zhang W, Lv J, Lv J, Yin A. BMSC s and miR-124a ameliorated diabetic nephropathy via inhibiting notch signalling pathway. J Cell Mol Med. 2018;22(10):4840-55.

78. Lv S, Liu G, Sun A, Wang J, Cheng J, Wang W, et al. Mesenchymal stem cells ameliorate diabetic glomerular fibrosis in vivo and in vitro by inhibiting TGF- $\beta$ signalling via secretion of bone morphogenetic protein 7. Diab Vasc Dis Res. 2014;11(4):251-61.

79. Bai Y, Wang J, He Z, Yang M, Li L, Jiang H. Mesenchymal stem cells reverse diabetic nephropathy disease via lipoxin A4 by targeting transforming growth factor $\beta$ (TGF- $\beta$ )/smad pathway and pro-inflammatory cytokines. Med Sci Monit: Int Med J Exp Clin Res. 2019;25:3069.

80. Ni W, Fang Y, Xie L, Liu X, Shan W, Zeng R, et al. Adipose-derived mesenchymal stem cells transplantation alleviates renal injury in streptozotocin-induced diabetic nephropathy. J Histochem Cytochem. 2015;63(11):842-53

81. Li Y, Liu J, Liao G, Zhang J, Chen Y, Li L, et al. Early intervention with mesenchymal stem cells prevents nephropathy in diabetic rats by ameliorating the inflammatory microenvironment. Int J Mol Med. 2018;41(5):2629-39.

82. Lee SE, Jang JE, Kim HS, Jung MK, Ko MS, Kim M-O, et al. Mesenchymal stem cells prevent the progression of diabetic nephropathy by improving mitochondrial function in tubular epithelial cells. Exp Mol Med. 2019;51(7):1-14.

83. Takemura S, Shimizu T, Oka M, Sekiya S, Babazono T. Transplantation of adipose-derived mesenchymal stem cell sheets directly into the kidney suppresses the progression of renal injury in a diabetic nephropathy rat model. J Diabetes Invest. 2020;11(3):545-53.

84. Sun C-K, Yen C-H, Lin Y-C, Tsai T-H, Chang L-T, Kao Y-H, et al. Autologous transplantation of adipose-derived mesenchymal stem cells markedly reduced acute ischemia-reperfusion lung injury in a rodent model. J Transl Med. 2011;9(1):1-13.

85. Wang S, Li Y, Zhao J, Zhang J, Huang Y. Mesenchymal stem cells ameliorate podocyte injury and proteinuria in a type 1 diabetic nephropathy rat model. Biol Blood Marrow Transplant. 2013;19(4):538-46.

86. Lv S-S, Liu G, Wang J-P, Wang W-W, Cheng J, Sun A-L, et al. Mesenchymal stem cells transplantation ameliorates glomerular injury in streptozotocin-induced diabetic nephropathy in rats via inhibiting macrophage infiltration. Int Immunopharmacol. 2013;17(2):275-82.

87. Lv S, Cheng J, Sun A, Li J, Wang W, Guan G, et al. Mesenchymal stem cells transplantation ameliorates glomerular injury in streptozotocininduced diabetic nephropathy in rats via inhibiting oxidative stress. Diabetes Res Clin Pract. 2014;104(1):143-54.

88. Lee KW, Kim TM, Kim KS, Lee S, Cho J, Park JB, et al. Renal ischemiareperfusion injury in a diabetic monkey model and therapeutic testing of human bone marrow-derived mesenchymal stem cells. J Diabetes Res. 2018;2018:1.

89. Rashed LA, Elattar S, Eltablawy N, Ashour H, Mahmoud LM, El-Esawy Y. Mesenchymal stem cells pretreated with melatonin ameliorate kidney functions in a rat model of diabetic nephropathy. Biochem Cell Biol. 2018;96(5):564-71.

90. Lang H, Dai C. Effects of bone marrow mesenchymal stem cells on plasminogen activator inhibitor-1 and renal fibrosis in rats with diabetic nephropathy. Arch Med Res. 2016;47(2):71-7.

91. Liu D, Zheng W, Pan S, Liu Z. Concise review: current trends on applications of stem cells in diabetic nephropathy. Cell Death Dis. 2020;11(11):1-14. 
92. Sávio-Silva C, Beyerstedt S, Soinski-Sousa PE, Casaro EB, Balby-Rocha MTA, Simplício-Filho A, et al. Mesenchymal stem cell therapy for diabetic kidney disease: a review of the studies using syngeneic, autologous, allogeneic, and xenogeneic cells. Stem Cells Int. 2020;2020:1.

93. Packham DK, Fraser IR, Kerr PG, Segal KR. Allogeneic mesenchymal precursor cells (MPC) in diabetic nephropathy: a randomized, placebocontrolled, dose escalation study. EBioMedicine. 2016;12:263-9.

94. Jafari D, Malih S, Eslami SS, Jafari R, Darzi L, Tarighi P, et al. The relationship between molecular content of mesenchymal stem cells derived exosomes and their potentials: opening the way for exosomes based therapeutics. Biochimie. 2019;165:76-89.

95. Moghaddam AS, Afshari JT, Esmaeili S-A, Saburi E, Joneidi Z, MomtaziBorojeni AA. Cardioprotective microRNAs: Lessons from stem cell-derived exosomal microRNAs to treat cardiovascular disease. Atherosclerosis. 2019;285:1-9.

96. Moghiman T, Barghchi B, Esmaeili S-A, Shabestari MM, Tabaee SS, Momtazi-Borojeni AA. Therapeutic angiogenesis with exosomal microRNAs: an effectual approach for the treatment of myocardial ischemia. Heart Failure Rev. 2020;26:1-9.

97. Yin Z, Yu M, Ma T, Zhang C, Huang S, Karimzadeh MR, et al. Mechanisms underlying low-clinical responses to PD-1/PD-L1 blocking antibodies in immunotherapy of cancer: a key role of exosomal PD-L1. J Immunother Cancer. 2021;9(1):e001698.

98. Zhou R, Wang L, Zhao G, Chen D, Song X, Momtazi-Borojeni AA, et al. Circulating exosomal microRNAs as emerging non-invasive clinical biomarkers in heart failure: mega bio-roles of a nano bio-particle. IUBMB Life. 2020;72(12):2546-62.

99. Tavasolian F, Hosseini AZ, Rashidi M, Soudi S, Abdollahi E, MomtaziBorojeni AA, et al. The impact of immune cell-derived exosomes on immune response initiation and immune system function. Curr Pharm Des. 2021;27(2):197-205.

100. Tavasolian F, Moghaddam AS, Rohani F, Abdollahi E, Janzamin E, Momtazi-Borojeni AA, et al. Exosomes: effectual players in rheumatoid arthritis. Autoimmunity Rev. 2020;19(6):102511.

101. Wei W, Ao Q, Wang X, Cao Y, Liu Y, Zheng SG, et al. Mesenchymal stem cell-derived exosomes: a promising biological tool in nanomedicine. Front Pharmacol. 2021;11:1954.

102. Viñas JL, Spence M, Gutsol A, Knoll W, Burger D, Zimpelmann J, et al. Receptor-ligand interaction mediates targeting of endothelial colony forming cell-derived exosomes to the kidney after ischemic injury. Sci Rep. 2018:8(1):1-12.

103. Wang $S$, Wen $X$, Han XR, Wang YJ, Shen $M$, Fan $S H$, et al. Repression of micro RNA-382 inhibits glomerular mesangial cell proliferation and extracellular matrix accumulation via FoxO1 in mice with diabetic nephropathy. Cell Prolif. 2018;51(5):e12462.

104. Tung CW, Hsu YC, Shih YH, Chang PJ, Lin CL. Glomerular mesangial cell and podocyte injuries in diabetic nephropathy. Nephrology. 2018;23:32-7.

105. Kitching AR, Hutton HL. The players: cells involved in glomerular disease. Clin J Am Soc Nephrol. 2016;11(9):1664-74.

106. Gallo S, Gili M, Lombardo G, Rossetti A, Rosso A, Dentelli P, et al. Stem cell-derived, microRNA-carrying extracellular vesicles: a novel approach to interfering with mesangial cell collagen production in a hyperglycaemic setting. PLoS ONE. 2016;11(9):e0162417.

107. Hao Y, Miao J, Liu W, Cai K, Huang X, Peng L. Mesenchymal stem cellderived exosomes carry MicroRNA-125a to protect against diabetic nephropathy by targeting histone deacetylase 1 and downregulating endothelin-1. Diabetes Metabolic Syndrome Obesity: Targets Therapy. 2021;14:1405

108. Xue C, Mei C-L. Polycystic kidney disease and renal fibrosis. Renal Fibrosis: Mechanisms and Therapies. 2019:81-100.

109. Liang X, Zhang L, Wang S, Han Q, Zhao RC. Exosomes secreted by mesenchymal stem cells promote endothelial cell angiogenesis by transferring miR-125a. J Cell Sci. 2016;129(11):2182-9.

110. Li C, Lei T. Rs 12976445 polymorphism is associated with risk of diabetic nephropathy through modulating expression of microRNA-125 and interleukin-6R. Med Sci Monit: Int Med J Exp Clin Res. 2015;21:3490.

111. Ahlborg G, Lindstrom J. Insulin sensitivity and big ET-1 conversion to ET-1 after ETA-or ETB-receptor blockade in humans. J Appl Physiol. 2002;93(6):2112-21.
112. Kasztan M, Pollock DM. Impact of ET-1 and sex in glomerular hyperfiltration in humanized sickle cell mice. Clin Sci. 2019;133(13):1475-86.

113. Zanatta CM, Veronese FV, Loreto MdS, Sortica DA, Carpio VN, Eldeweiss MIA, et al. Endothelin-1 and endothelin a receptor immunoreactivity is increased in patients with diabetic nephropathy. Ren Fail. 2012;34(3):308-15.

114. Badr KF, Murray J, Breyer M, Takahashi K, Inagami T, Harris R. Mesangial cell, glomerular and renal vascular responses to endothelin in the rat kidney. Elucidation of signal transduction pathways. J Clin Investig. 1989;83(1):336-42.

115. Ergul A. Endothelin-1 and diabetic complications: focus on the vasculature. Pharmacol Res. 2011;63(6):477-82.

116. Daehn IS, Duffield JS. The glomerular filtration barrier: a structural target for novel kidney therapies. Nat Rev Drug Discov. 2021;20:1-19.

117. Nakamichi R, Hayashi $\mathrm{K}$, Itoh $\mathrm{H}$. Effects of high glucose and lipotoxicity on diabetic podocytes. Nutrients. 2021;13(1):241.

118. Jin J, Shi Y, Gong J, Zhao L, Li Y, He Q, et al. Exosome secreted from adipose-derived stem cells attenuates diabetic nephropathy by promoting autophagy flux and inhibiting apoptosis in podocyte. Stem Cell Res Ther. 2019;10(1):1-15.

119. Duan Y, Luo Q, Wang Y, Ma Y, Chen F, Zhu X, et al. Adipose mesenchymal stem cell-derived extracellular vesicles containing microRNA-26a-5p target TLR4 and protect against diabetic nephropathy. J Biol Chem. 2020;295(37):12868-84.

120. Yi M, Zhang L, Liu Y, Livingston MJ, Chen J-K, Nahman NS Jr, et al. Autophagy is activated to protect against podocyte injury in adriamycin-induced nephropathy. Am J Physiol-Renal Physiol. 2017;313(1):F74-84.

121. Gödel M, Hartleben B, Herbach N, Liu S, Zschiedrich S, Lu S, et al. Role of mTOR in podocyte function and diabetic nephropathy in humans and mice. J Clin Investig. 2011;121(6):2197-209.

122. Ying $\mathrm{Q}, \mathrm{Wu}$ G. Molecular mechanisms involved in podocyte EMT and concomitant diabetic kidney diseases: an update. Ren Fail. 2017;39(1):474-83.

123. Jin J, Wang Y, Zhao L, Zou W, Tan M, He Q. Exosomal miRNA-215-5p derived from adipose-derived stem cells attenuates epithelial-mesenchymal transition of podocytes by inhibiting ZEB2. BioMed Res Int. 2020;2020:1.

124. Hou Y, Zhen J, Xu X, Zhen K, Zhu B, Pan R, et al. miR-215 functions as a tumor suppressor and directly targets ZEB2 in human non-small cell lung cancer. Oncol Lett. 2015;10(4):1985-92.

125. Nam E-H, Lee Y, Park Y-K, Lee JW, Kim S. ZEB2 upregulates integrin a5 expression through cooperation with Sp1 to induce invasion during epithelial-mesenchymal transition of human cancer cells. Carcinogenesis. 2012;33(3):563-71.

126. Comijn J, Berx G, Vermassen P, Verschueren K, van Grunsven L, Bruyneel $\mathrm{E}$, et al. The two-handed $\mathrm{E}$ box binding zinc finger protein SIP1 downregulates E-cadherin and induces invasion. Mol Cell. 2001;7(6):1267-78.

127. Bharadwaj S, Liu G, Shi Y, Wu R, Yang B, He T, et al. Multipotential differentiation of human urine-derived stem cells: Potential for therapeutic applications in urology. Stem cells. 2013;31(9):1840-56.

128. Ouyang B, Sun X, Han D, Chen S, Yao B, Gao Y, et al. Human urinederived stem cells alone or genetically-modified with FGF2 Improve type 2 diabetic erectile dysfunction in a rat model. PLOS ONE. 2014;9(3):e92825.

129. Jiang Z-z, Liu Y-m, Niu X, Yin J-y, Hu B, Guo S-c, et al. Exosomes secreted by human urine-derived stem cells could prevent kidney complications from type I diabetes in rats. Stem Cell Res Therapy. 2016;7(1):1-13.

130. Duan YR, Chen BP, Chen F, Yang SX, Zhu CY, Ma YL, et al. Exosomal microRNA-16-5p from human urine-derived stem cells ameliorates diabetic nephropathy through protection of podocyte. J Cellular Mol Med. 2019;256:10798.

131. Stevens M, Oltean S. Modulation of VEGF-A alternative splicing as a novel treatment in chronic kidney disease. Genes. 2018;9(2):98.

132. Bus P, Scharpfenecker M, Van Der Wilk P, Wolterbeek R, Bruijn JA, Baelde HJ. The VEGF-A inhibitor sFLT-1 improves renal function by reducing endothelial activation and inflammation in a mouse model of type 1 diabetes. Diabetologia. 2017;60(9):1813-21.

133. Marjani A, Shirafkan A. The metabolic syndrome in type 2 diabetic patients in Gorgan: according to NCEP ATPIII and IDF definitions. Diabetes Metab Syndr. 2011;5(4):207-10. 
134. Nagaishi K, Mizue Y, Chikenji T, Otani M, Nakano M, Saijo Y, et al. Umbilical cord extracts improve diabetic abnormalities in bone marrowderived mesenchymal stem cells and increase their therapeutic effects on diabetic nephropathy. Sci Rep. 2017;7(1):1-17

135. Grange C, Tritta S, Tapparo M, Cedrino M, Tetta C, Camussi G, et al. Stem cell-derived extracellular vesicles inhibit and revert fibrosis progression in a mouse model of diabetic nephropathy. Sci Rep. 2019;9(1):1-13.

136. Mao R, Shen J, Hu X. BMSCs-derived exosomal microRNA-let-7a plays a protective role in diabetic nephropathy via inhibition of USP22 expression. Life Sci. 2021;268:118937.

137. Huang K-P, Chen C, Hao J, Huang J-Y, Liu P-Q, Huang H-Q. AGEs-RAGE system down-regulates Sirt1 through the ubiquitin-proteasome pathway to promote FN and TGF- $\beta 1$ expression in male rat glomerular mesangial cells. Endocrinology. 2015;156(1):268-79.

138. Wu J, Zheng C, Fan Y, Zeng C, Chen Z, Qin W, et al. Downregulation of microRNA-30 facilitates podocyte injury and is prevented by glucocorticoids. J Am Soc Nephrol. 2014;25(1):92-104.

139. Meng XM, Huang XR, Xiao J, Chen Hy, Zhong $X$, Chung AC, et al. Diverse roles of TGF- $\beta$ receptor $\|$ in renal fibrosis and inflammation in vivo and in vitro. J Pathol. 2012;227(2):175-88.

140. Peng R, Liu H, Peng H, Zhou J, Zha H, Chen X, et al. Promoter hypermethylation of let-7a-3 is relevant to its down-expression in diabetic nephropathy by targeting UHRF1. Gene. 2015;570(1):57-63.

141. Zhou J, Peng R, Li T, Luo X, Peng H, Zha H, et al. A potentially functional polymorphism in the regulatory region of let-7a- 2 is associated with an increased risk for diabetic nephropathy. Gene. 2013;527(2):456-61.

142. Yan N, Wen L, Peng R, Li H, Liu H, Peng H, et al. Naringenin ameliorated kidney injury through Let-7a/TGFBR1 signaling in diabetic nephropathy. J Diabetes Res. 2016;2016:1.

143. Shi J-x, Wang Q-j, Li H, Huang Q. Silencing of USP22 suppresses high glucose-induced apoptosis, ROS production and inflammation in podocytes. Molecular BioSystems. 2016;12(5):1445-56.

144. Nagaishi K, Mizue Y, Chikenji T, Otani M, Nakano M, Konari N, et al. Mesenchymal stem cell therapy ameliorates diabetic nephropathy via the paracrine effect of renal trophic factors including exosomes. Sci Rep. 2016;6(1):1-16.

145. Ebrahim N, Ahmed IA, Hussien NI, Dessouky AA, Farid AS, Elshazly AM, et al. Mesenchymal stem cell-derived exosomes ameliorated diabetic nephropathy by autophagy induction through the mTOR signaling pathway. Cells. 2018;7(12):226.

146. Cai X, Zou F, Xuan R, Lai X-Y. Exosomes from mesenchymal stem cells expressing microribonucleic acid-125b inhibit the progression of diabetic nephropathy via the tumour necrosis factor receptor-associated factor 6/Akt axis. Endocrine J. 2021:EJ20-0619.

147. Wang B, Yao K, Huuskes BM, Shen H-H, Zhuang J, Godson C, et al. Mesenchymal stem cells deliver exogenous microRNA-let7c via exosomes to attenuate renal fibrosis. Mol Ther. 2016:24(7):1290-301.

148. Street J, Koritzinsky E, Glispie D, Star R, Yuen P. Urine exosomes: an emerging trove of biomarkers. Adv Clin Chem. 78: Elsevier; 2017. p. $103-22$.

149. Lässer C, Alikhani VS, Ekström K, Eldh M, Paredes PT, Bossios A, et al. Human saliva, plasma and breast milk exosomes contain RNA: uptake by macrophages. J Transl Med. 2011 14;9:9. PubMed PMID: 21235781. Pubmed Central PMCID: PMC3033821. Epub 2011/01/18. eng.

150. Nik Mohamed Kamal N, Shahidan WNS. Non-Exosomal and Exosomal Circulatory MicroRNAs: Which Are More Valid as Biomarkers? Front Pharmacol. 2019;10:1500. PubMed PMID: 32038230. Pubmed Central PMCID: PMC6984169. Epub 2020/02/11. eng

151. Ramachandran S, Palanisamy V. Horizontal transfer of RNAs: exosomes as mediators of intercellular communication. Wiley Interdisciplinary Reviews: RNA. 2012;3(2):286-93.

152. Cazzoli R, Buttitta F, Di Nicola M, Malatesta S, Marchetti A, Rom WN, et al. microRNAs derived from circulating exosomes as noninvasive biomarkers for screening and diagnosing lung cancer. 2013;8(9):1156-62.

153. Endzelinš̌ E, Berger A, Melne V, Bajo-Santos C, Soboḷevska K, Ābols $A$, et al. Detection of circulating miRNAs: comparative analysis of extracellular vesicle-incorporated miRNAs and cell-free miRNAs in whole plasma of prostate cancer patients. BMC Cancer. 2017 Nov 9;17(1):730. PubMed PMID: 29121858. Pubmed Central PMCID: PMC5679326. Epub 2017/11/11. eng.
154. Gallo A, Tandon M, Alevizos I, Illei GG. The majority of microRNAs detectable in serum and saliva is concentrated in exosomes. PLoS One. 2012;7(3):e30679. PubMed PMID: 22427800. Pubmed Central PMCID: PMC3302865. Epub 2012/03/20. eng.

155. Lv L-L, Cao Y, Liu D, Xu M, Liu H, Tang R-N, et al. Isolation and quantification of microRNAs from urinary exosomes/microvesicles for biomarker discovery. Int J Biol Sci. 2013;9(10):1021.

156. Barutta F, Tricarico M, Corbelli A, Annaratone L, Pinach S, Grimaldi S, et al. Urinary exosomal microRNAs in incipient diabetic nephropathy. PLoS One. 2013;8(11):e73798.

157. Harvey SJ, Jarad G, Cunningham J, Goldberg S, Schermer B, Harfe $B D$, et al. Podocyte-specific deletion of dicer alters cytoskeletal dynamics and causes glomerular disease. J Am Soc Nephrol. 2008;19(11):2150-8.

158. Eissa S, Matboli M, Bekhet MM. Clinical verification of a novel urinary microRNA panal: 133b,-342 and-30 as biomarkers for diabetic nephropathy identified by bioinformatics analysis. Biomed Pharmacother. 2016;83:92-9.

159. Wang Y, Fu B, Sun X, Li D, Huang Q, Zhao W, et al. Differentially expressed microRNAs in bone marrow mesenchymal stem cellderived microvesicles in young and older rats and their effect on tumor growth factor- $\beta 1$-mediated epithelial-mesenchymal transition in HK2 cells. Stem Cell Res Ther. 2015;6(1):1-11.

160. Khalyfa A, Kheirandish-Gozal L, Bhattacharjee R, Khalyfa AA, Gozal D. Circulating microRNAs as potential biomarkers of endothelial dysfunction in obese children. Chest. 2016;149(3):786-800.

161. Kim J-W, You Y-H, Jung S, Suh-Kim H, Lee I-K, Cho J-H, et al. miRNA30a-5p-mediated silencing of Beta2/NeuroD expression is an important initial event of glucotoxicity-induced beta cell dysfunction in rodent models. Diabetologia. 2013;56(4):847-55.

162. Zhang W, Zhang C, Chen H, Li L, Tu Y, Liu C, et al. Evaluation of microRNAs miR-196a, miR-30a-5P, and miR-490 as biomarkers of disease activity among patients with FSGS. Clin J Am Soc Nephrol. 2014;9(9):1545-52.

163. Xie $Y$, Jia $Y$, Cuihua $X$, Hu F, Xue M, Xue Y. Urinary exosomal microRNA profiling in incipient type 2 diabetic kidney disease. Journal of diabetes research. 2017;2017.

164. Eissa S, Matboli M, Aboushahba R, Bekhet MM, Soliman Y. Urinary exosomal microRNA panel unravels novel biomarkers for diagnosis of type 2 diabetic kidney disease. J Diabetes Complications. 2016;30(8):1585-92.

165. Zhao Y, Shen A, Guo F, Song Y, Jing N, Ding X, et al. Urinary Exosomal MiRNA-4534 as a Novel Diagnostic Biomarker for Diabetic Kidney Disease. Front Endocrinol. 2020;11:590.

166. Tsai Y-C, Kuo M-C, Hung W-W, Wu L-Y, Wu P-H, Chang W-A, et al. High glucose induces mesangial cell apoptosis through miR-15b-5p and promotes diabetic nephropathy by extracellular vesicle delivery. Mol Ther. 2020;28(3):963-74.

167. Delić D, Eisele C, Schmid R, Baum P, Wiech F, Gerl M, et al. Urinary exosomal miRNA signature in type II diabetic nephropathy patients. PLoS One. 2016:11(3):e0150154.

168. Daniel C, Wiede J, Krutzsch HC, Ribeiro SM, Roberts DD, MurphyUllrich JE, et al. Thrombospondin-1 is a major activator of TGF- $\beta$ in fibrotic renal disease in the rat in vivo. Kidney Int. 2004;65(2):459-68.

169. Ahamed J, Janczak CA, Wittkowski KM, Coller BS. In vitro and in vivo evidence that thrombospondin-1 (TSP-1) contributes to stirring-and shear-dependent activation of platelet-derived TGF- $\beta 1$. PLoS One. 2009:4(8):e6608.

170. Wahab N, Schaefer L, Weston B, Yiannikouris O, Wright A, Babelova $A$, et al. Glomerular expression of thrombospondin-1, transforming growth factor beta and connective tissue growth factor at different stages of diabetic nephropathy and their interdependent roles in mesangial response to diabetic stimuli. Diabetologia. 2005;48(12):2650-60

171. Hohenstein B, Daniel C, Hausknecht B, Boehmer K, Riess R, Amann $\mathrm{KU}$, et al. Correlation of enhanced thrombospondin-1 expression, TGF- $\beta$ signalling and proteinuria in human type-2 diabetic nephropathy. Nephrol Dial Transplant. 2008;23(12):3880-7.

172. Li W, Yang S, Qiao R, Zhang J. Potential Value of Urinary ExosomeDerived let-7c-5p in the Diagnosis and Progression of Type II Diabetic Nephropathy. Clin Lab. 2018;64(5):709-18. 
173. Wang B, Jha JC, Hagiwara S, McClelland AD, Jandeleit-Dahm K, Thomas $M C$, et al. Transforming growth factor- $\beta 1$-mediated renal fibrosis is dependent on the regulation of transforming growth factor receptor 1 expression by let-7b. Kidney Int. 2014;85(2):352-61.

174. Brennan EP, Nolan KA, Börgeson E, Gough OS, McEvoy CM, Docherty $\mathrm{NG}$, et al. Lipoxins attenuate renal fibrosis by inducing let-7c and suppressing TGFßR1. J Am Soc Nephrol. 2013;24(4):627-37.

175. Zang J, Maxwell AP, Simpson DA, McKay GJ. Differential expression of urinary exosomal microRNAs miR-21-5p and miR-30b-5p in individuals with diabetic kidney disease. Sci Rep. 2019;9(1):1-10.

176. Kim H, Bae Y-U, Jeon JS, Noh H, Park HK, Byun DW, et al. The circulating exosomal microRNAs related to albuminuria in patients with diabetic nephropathy. J Transl Med. 2019;17(1):1-11.

177. Mahabeleshwar GH, Feng W, Phillips DR, Byzova TV. Integrin signaling is critical for pathological angiogenesis. J Exp Med. 2006;203(11):2495-507.

178. Gao C, Wang B, Chen Q, Wang M, Fei X, Zhao N. Serum exosomes from diabetic kidney disease patients promote pyroptosis and oxidative stress through the miR-4449/HIC1 pathway. Nutr Diabetes. 2021;11(1):1-9.

179. Yang Y, Lv X, Fan Q, Wang X, Xu L, Lu X, et al. Analysis of circulating IncRNA expression profiles in patients with diabetes mellitus and diabetic nephropathy: differential expression profile of circulating IncRNA. Clin Nephrol. 2019;92(1):25.

180. LV J, Wu Y, Mai Y, Bu S. Noncoding rnas in diabetic nephropathy: Pathogenesis, biomarkers, and therapy. Journal of Diabetes Research. 2020;2020.

181. Ibrahim AA, Soliman HM, El-Lebedy D, Hassan M, Helmy NA, Hamid TAA, et al. Expression of exosomal miR-21 and miR-29 in serum of children and adolescents with T1DM and persistent microalbuminuria. Gene Rep. 2019;16:100461.

182. Massart J, Sjögren RJ, Lundell LS, Mudry JM, Franck N, O'Gorman DJ, et al. Altered miR-29 expression in type 2 diabetes influences glucose and lipid metabolism in skeletal muscle. Diabetes. 2017;66(7):1807-18.

183. Nielsen LB, Wang C, Sørensen K, Bang-Berthelsen CH, Hansen L, Andersen M-LM, et al. Circulating levels of microRNA from children with newly diagnosed type 1 diabetes and healthy controls: evidence that miR-25 associates to residual beta-cell function and glycaemic control during disease progression. Experimental diabetes research. 2012;2012, 1.

184. Kong L, Zhu J, Han W, Jiang X, Xu M, Zhao Y, et al. Significance of serum microRNAs in pre-diabetes and newly diagnosed type 2 diabetes: a clinical study. Acta Diabetol. 2011;48(1):61-9.

185. Chien H-Y, Chen C-Y, Chiu Y-H, Lin Y-C, Li W-C. Differential microRNA profiles predict diabetic nephropathy progression in Taiwan. Int J Med Sci. 2016;13(6):457.

186. Mohan A, Singh RS, Kumari M, Garg D, Upadhyay A, Ecelbarger CM, et al. Urinary exosomal microRNA-451-5p is a potential early biomarker of diabetic nephropathy in rats. PLoS ONE. 2016;1 1(4):e0154055.

187. Liu D, Liu F, Li Z, Pan S, Xie J, Zhao Z, et al. HNRNPA1-mediated exosomal sorting of miR-483-5p out of renal tubular epithelial cells promotes the progression of diabetic nephropathy-induced renal interstitial fibrosis. Cell Death Dis. 2021;12(3):1-15.

\section{Publisher's Note}

Springer Nature remains neutral with regard to jurisdictional claims in published maps and institutional affiliations.

Ready to submit your research? Choose BMC and benefit from:

- fast, convenient online submission

- thorough peer review by experienced researchers in your field

- rapid publication on acceptance

- support for research data, including large and complex data types

- gold Open Access which fosters wider collaboration and increased citations

- maximum visibility for your research: over $100 \mathrm{M}$ website views per year

At BMC, research is always in progress.

Learn more biomedcentral.com/submissions 